\title{
NIST Calibration of ASTM E127-Type Ultrasonic Reference Blocks
}

\section{J. A. Slotwinski \\ G. V. Blessing}

U.S. DEPARTMENT OF COMMERCE Technology Administration National Institute of Standards and Technology Ultrasonics Group

Manufacturing Engineering Laboratory Gaithersburg, MD 20899 



\section{NIST Calibration of ASTM E127-Type Ultrasonic Reference Blocks}

\section{J. A. Slotwinskl \\ G. V. Blessing}

U.S. DEPARTMENT OF COMMERCE Technology Administration

National Institute of Standards

and Technology

Ultrasonics Group

Manufacturing Engineering Laboratory

Gaithersburg, MD 20899

May 1994

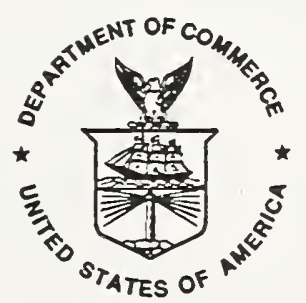

U.S. DEPARTMENT OF COMMERCE Ronald H. Brown, Secretary

TECHNOLOGY ADMINISTRATION Mary L Good, Under Secretary for Technology

NATIONAL INSTITUTE OF STANDARDS AND TECHNOLOGY

Arati Prabhakar, Director 



\section{TABLE OF CONTENTS}

Introduction $\quad 1$

E127-Type Reference Blocks $\quad 2$

$\begin{array}{lr}\text { Measurement Facility } & 2\end{array}$

$\begin{array}{lr}\text { Instrumentation } & 3\end{array}$

$\begin{array}{ll}\text { Transducer } & 3\end{array}$

Pulser/Receiver $\quad 4$

PT-4 Tuning Circuit $\quad 5$

RC Circuit/Digital Voltmeter $\quad 6$

$\begin{array}{lr}\text { Calibration Procedures } & 6\end{array}$

$\begin{array}{ll}\text { Preliminary Settings } & 6\end{array}$

$\begin{array}{ll}\text { Distance-Amplitude (D-A) Sets } & 7\end{array}$

Area-Amplitude (A-A) Sets $\quad 8$

Calibration Report Contents $\quad 8$

$\begin{array}{lr}\text { NIST Ultrasonic Calibration Databases } & 8\end{array}$

Calibration Database $\quad 8$

Check-Standard Database $\quad 9$

$\begin{array}{lr}\text { Conclusion } & 9\end{array}$

$\begin{array}{lr}\text { Acknowledgments } & 10\end{array}$

$\begin{array}{ll}\text { References } & 11\end{array}$

$\begin{array}{ll}\text { Appendix I: } & 13\end{array}$

Procedures for Requesting Ultrasonic Reference Block Calibrations

Appendix II: $\quad 15$

Data-Acquisition Forms used in NIST Calibrations of ASTM E127-Type Reference Blocks

$\begin{array}{ll}\text { Appendix III: } & 19\end{array}$

Sample Distance-Amplitude Calibration Report

Tables

$\begin{array}{lr}\text { Figures } & 24\end{array}$ 



\section{$\underline{\text { Introduction }}$}

This document describes the procedures and instrumentation used by the National Institute of Standards and Technology (NIST) in calibrating aluminum ultrasonic reference blocks. The Ultrasonics Group, in the Automated Production Technology Division of the Manufacturing Engineering Laboratory, performs this calibration service for technological and industrial customers. The calibration is based on the American Society of Testing and Materials (ASTM) recognized practice for calibrating aluminum reference blocks, designated E127-92a: Standard Practice for Fabricating and Checking Aluminum Alloy Ultrasonic Standard Reference Blocks [1] ${ }^{1}$. Instructions for requesting calibrations of ultrasonic reference blocks are contained in Appendix I of this document.

The NIST ultrasonic reference block calibration service was originated in the late 1970 's, and is described in the NBS Technical Note 924 entitled "Procedures for the Calibration of ASTM E127-Type Ultrasonic Reference Blocks." [2]. At that time the application of one master block for use as a reference standard was considered to be a temporary or interim measure. Today NIST uses this master block to set the ultrasonic system sensitivity in all calibrations of ultrasonic reference block sets. In addition, there are several newly implemented practices employed for checking the calibration system characteristics, both over a period of years and in preparation for a particular calibration. This current document updates the NBS Technical Note 924 in describing these practices for our calibration procedure.

\footnotetext{
${ }^{1}$ Steel and Titanium Ultrasonic reference blocks are also calibrated by NIST. While E127-92a does not apply to these types of blocks, the instrumentation and some of the procedures described in this document are the same. ASTM E428: Fabrication and Control of Steel Reference Blocks used in Ultrasonic Inspection covers these types of blocks.
} 


\section{E127-Type Ultrasonic Reference Blocks}

The reference artifacts described in E127 are 7075-T6 aluminum alloy, $50.8 \mathrm{~mm}$ (2 in $)^{2}$ diameter cylindrical blocks. Following NIST policy, we give quantities in SI units with in-lb units in parentheses. The ASTM E127 standard generally gives the in-lb units first. The blocks are of varying length and have flat-bottom-holes (FBH) drilled into their bottom surfaces. A schematic of this type of block is shown in Fig. 1. In describing these types of blocks the following labeling convention is used in E127: the hole diameter, expressed in 64ths of an inch, and the metal path length, expressed in $10^{-2}$ of an inch, are separated by a dash. For example, a block with a $5 / 64$ in diameter hole (also referred to as a No. 5 hole) and a 0.50 in metal path would be designated as 5-0050. Blocks with this labeling are commonly used; however, E127 gives equivalent hole diameters and lengths in SI units. This labeling convention is used throughout this document, but quantities will generally be given in accord with NIST policy.

\section{Measurement Facility}

A thorough understanding of the ultrasonic calibration equipment is essential in order to maintain a consistent and repeatable calibration service. Changes in the calibration system can be detected, corrected, and even anticipated when one has a sufficient understanding and historical charting of the instrumentation involved. The past two decades have provided us with the data and experience necessary to understand which measurement factors are important for reliably calibrating aluminum ultrasonic reference blocks.

All reference block calibrations are done in a $300 \mathrm{~L}$ tank, as shown in Fig. 2. Distilled water, with a nominal temperature range of $20-24{ }^{\circ} \mathrm{C}$, is used as the coupling fluid. Previous research has shown that temperature variations in this range do not affect the calibration results when all components are in thermal equilibrium [3]. The water is kept chlorinated in order to prevent algae growth, etc., and while the conductivity of the water is increased as a result, the short-term exposure of the blocks to the water is not harmful to the physical characteristics of the blocks. In addition, a filtration system is periodically used to keep the coupling fluid clean of small debris such as dust. Calibration blocks are placed in the tank on a set of large aluminum steps, machined to a high precision, which keep all of the blocks' front-surfaces at the same height. This minimizes the amount of vertical transducer manipulation needed during the calibration procedure.

A large moveable stage is attached to the top of the tank, as shown in Fig. 2. The ultrasonic transducer is connected to this stage by means of a $98 \mathrm{~cm}$ long ultra-highfrequency (UHF) coaxial metal rod. The transducer can be manually manipulated in two perpendicular planes through the use of an angulator. The transducer also has degrees of

\footnotetext{
${ }^{2}$ English units are given first with SI units in parentheses by ASTM in E127 in describing reference blocks and transducer characteristics. This is contrary to the U.S. national policy of using metric units only. However, this document lists both the English and metric equivalent of measured quantities in a manner consistent with NIST policy to provide coherency for those who are familiar with E127. NIST is currently working with ASTM to promote the use of metric units only.
} 
freedom in the $-X,-Y$, and $-Z$ directions, with movement in these directions controlled manually or with motorized linear actuators contained within the stage. This setup is sufficient for properly positioning the transducer during all phases of the calibration.

\section{Instrumentation}

Figure 3 shows a schematic of the ultrasonic calibration instrumentation. Each component of this setup is explained in detail below. ${ }^{3}$

\section{Transducer}

One of the most important components of the calibration system is the ultrasonic transducer. Ultrasonic transducers convert electrical pulse-excitations into pulses of highfrequency sound which are above the threshold of human hearing (in this case $5 \mathrm{MHz}$ ). Pulse repetition rates of 200-1000 s-1 are typically used in this calibration. The ultrasonic pulses are emitted from the transducer and travel through a water medium (i.e. coupling) to the target of interest. At a material interface or discontinuity some of the ultrasonic energy is reflected back towards the transducer. The transducer then receives these reflected echoes and converts them back into electrical signals for electronic detection. For a given ultrasonic pulse incident on a target, the amplitude of the return echo depends on the target size and shape, and on the acoustic properties of both the target and the coupling medium. The measurement parameter of interest in the calibration of ultrasonic reference blocks is the amplitude of the return echoes reflected from the flat-bottom-holes drilled into the bottom of the blocks. In this particular calibration, the interface of interest is a solid-air boundary between the solid aluminum and the FBH.

An Aerotech $5 \mathrm{MHz}$ quartz immersion-type transducer possessing a $9.525 \mathrm{~mm}$ (0.375 in) effective element size, historically designated "Lab-Standard-4" (LS-4) [4], has been used in virtually all of NIST's ultrasonic reference block calibrations since the inception of the calibration service. Quartz transducers, while not commonly used for generic nondestructive testing due to their insensitivity, do have the advantage of remaining very stable over long periods of use. In addition, quartz transducers are more easily constructed to the same or similar performance characteristics, than are ceramic units [4]. Similarity in performance between like-constructed transducers is important for maintaining widespread applicability of the ASTM E127-92a measurement standard when using different equipment. The pulsed beam-profile characteristics of LS-4 have been carefully and repeatedly measured over time using pulse-echo techniques with specific targets. We note that LS -4 meets the requirements of section 11.5 of E127-92a in size, operating frequency, and lateral and axial beam profiles. The transducer beam profiles, taken on a $12.7 \mathrm{~mm}(0.5 \mathrm{in})$ diameter steel sphere target, are shown in Figs. 4-6. Figure

\footnotetext{
${ }^{3}$ Commercial equipment or materials are identified in this paper in order to specify adequately certain calibration procedures. In no case does such identification imply recommendation or endorsement by the National Institute of Standards and Technology, nor does it imply that the material or equipment identified is necessarily the best available for the purpose.
} 
4a shows lateral scans of LS-4 taken at the transducer's near-field $\left(Y_{0}^{+}\right)$length. ${ }^{4}$ The scans are taken at four different rotational orientations of the transducer which are separated by $45^{\circ}$ of rotation. Figure $4 \mathrm{~b}$ shows a comparison of one of the $4 \mathrm{a}$ scans with one which was taken by Chwirut in 1976 [2]. Figure 5 is a lateral scan of LS-4 taken at the transducer's near-field minimum $\left(Y_{1}^{-}\right)$point. Figure 6 is an axial scan of LS-4 which clearly shows the $Y_{0}^{+}$and $Y_{1}^{-}$points in the transducer's sound field. All of the beam profiles taken at the present time are in good agreement with those obtained by Chwirut in the 1970's [2], indicating that the transducer's response has not measurably changed with time.

To complement the pulse-echo scans, hydrophone scans have recently been made of the transducer's beam profile. A thin polymer membrane, made of polyvinyldifluoride (PVDF) in this case, can measure ultrasonic pulses traveling through it in either direction, with minimal perturbation to the pulses themselves. Ultrasonic pulses measured by traditional transducers are affected by the transfer-function characteristics of the transducer, resulting in a measured waveform that differs from the actual waveform. In contrast, the significantly greater bandwidth and closer impedance match to water of a PVDF hydrophone allows for a high fidelity recording of the actual ultrasonic waveform. A commercially available hydrophone possessing a circular element size of $0.3 \mathrm{~mm}^{2}$ $\left(0.0005 \mathrm{in}^{2}\right)$ and a bandwidth $\geq 20 \mathrm{MHz}$ was used to map the ultrasonic beam intensity at the transducer's near-field $\left(Y_{0}^{+}\right)$length. The transducer was moved slowly over a $645 \mathrm{~mm}^{2}$ $\left(1 \mathrm{in}^{2}\right)$ area in a raster-scan fashion. The result, shown in Fig. 7, shows a good symmetric beam profile which is free of significant irregularities.

\section{Pulser/Receiver}

The pulser/receiver currently used in NIST's calibration service is an Automation Industries Inc. model M90 Reflectoscope. When this unit is used in conjunction with an external LC tuning circuit, it provides pulse excitations of sufficient energy to drive the requisite quartz transducers such as LS-4. The receiver has a coarse-adjustment bandwidth extending to $10 \mathrm{MHz}$ and a gain range of approximately $0-81 \mathrm{~dB}$. This gain is adjustable by a $20 \mathrm{~dB}$-increment switch (range $0-40 \mathrm{~dB}$ ), a $2 \mathrm{~dB}$-increment knob (range 0 $30 \mathrm{~dB}$ ), a $1 \mathrm{~dB}$-increment switch (range $0-1 \mathrm{~dB}$ ), and a continuous gain vernier (range 0 $10 \mathrm{~dB}$.) This gain range is sufficient for adequately detecting the ultrasonic reflections from FBHs for the metal-paths and hole sizes specified in E127-92a. When making appropriate gain changes during calibrations, the labeled gain values indicated on the M90 are not used. Rather, the amplitude of the reflected signal is used to measure gain changes, as described later in this document.

\footnotetext{
${ }^{4}$ The transducer's near field length is the natural focus distance in an ultrasonic beam emanating from a flat transducer. The sound field intensity monotonically decreases beyond this length, and is therefore generally a better region for target placement. The near field length $\mathrm{N}$ of a circular spot source, in a coupling fluid, can be approximated analytically by the expression:

$$
N=\frac{D^{2}}{4 \lambda}
$$

where $\mathrm{D}$ is the transducer's active element diameter and $\lambda$ is the wavelength of the ultrasound in the coupling fluid. Note that $\lambda$ varies inversely with the frequency of the ultrasound.
} 
The receiver linearity of the M90 Reflectoscope is checked periodically, using the setup shown in Fig. 8. A function generator is used to generate a signal pulse which has a similar spectral content as a typical echo received by the M90 and LS-4 located $88.9 \mathrm{~mm}$ (3.5 in, its $Y_{0}^{+}$point), from the surface of a reference block target in water. This signal is attenuated by an independently calibrated attenuation strip, and then detected by the M90 through its receiver port. The attenuation strip is calibrated using a regulated DG source and has a standard uncertainty of $\pm 0.1 \mathrm{~dB}$ to $\pm 0.3 \mathrm{~dB}$ over the range of $1 \mathrm{~dB}$ to $60 \mathrm{~dB}$. A digital voltmeter measures the peak amplitude of the unattenuated input signal and the subsequent attenuated signals. The detected peak amplitude is then compared to the value computed using the unattenuated signal amplitude and the attenuation value. This is repeated over a range of attenuation values, for each of several different receiver gain settings on the M90. A typical linearity test for one receiver gain setting is shown in Fig. 9. The receiver portion of the M90 has a measured amplitude linearity of better than 1.5 $\%$ of full-scale (FS), over a range of amplitude values that exceed those normally used in these calibrations. (While the M90 is linear within $1.5 \%$ FS up to $6 \mathrm{~V}, 0.3-5.0 \mathrm{~V}$ has been defined to be the instrument's full scale linear range.)

In the calibration, the ultrasonic signal of interest is selected on the M90 screen for measurement by positioning the M90's receiver gate. The peak amplitude of the signal marked by this electronic gate is then detected by the M90 and delivered to a digital voltmeter. An adjustable pulse-length knob on the M90 is kept at its maximum (full clock-wise) position at all times. The M90 shock-excitation is then tuned with an external tuning circuit described below.

\section{PT-4 Tuning Circuit}

The PT-4 tuning circuit indicated in the general calibration setup of Fig. 3 is used as an external tuner for the shock-excitation pulses from the M90 Reflectoscope that drive quartz transducers. The circuit is a commercial one, built by F. Baxter Co., and distributed by Eastern NDT [5] for use with low capacitance transducers. A schematic for this circuit is shown in Fig. 10. This circuit, which is external to the M90, is needed since the M90 is a shock-excitation pulser without the internal tuning capability for the tuned excitation specified in E127-92a. Together these two units very closely approximate the performance (when used with the same quartz transducer) of the calibration pulser/receiver unit used by NIST in the 1970's and 80's.

Experience has shown that an important aspect of a reliable ultrasonic calibration system is maintaining the constancy of the frequency content of this excitation pulse. As a matter of practice the excitation pulse of the calibration system is periodically checked, and tuned if necessary. The experimental setup for this procedure is shown in Fig. 11. The transducer is attached to the system in its normal way and immersed in water so as to maintain the usual physical loading on the transducer. The M90 shock-excitation pulse is observed on an oscilloscope and its frequency content is measured on a calibrated spectrum analyzer. If necessary, the pulse length and tuning are adjusted, using the control knobs (variable resistor for pulse length and variable capacitor for pulse tuning) in the PT-4 circuit. The spectral content of this shock-excitation is tuned to have a centerfrequency of $5.00 \mathrm{MHz} \pm 0.05 \mathrm{MHz}$. A typical excitation pulse from the $\mathrm{M} 90$, with the 
PT-4 tuning circuit, and its corresponding frequency spectrum are shown in Fig. 12. In the time domain this pulse resembles a damped one-and-a-half period sinusoidal pulse.

One variable which affects the frequency content of the excitation pulse reaching the transducer is the length of the BNC cables and UHF rod between the pulser and transducer. Longer cables result in a higher capacitance between the various pieces of instrumentation used in the calibration. The higher capacitance affects the system's capability of properly tuning the transducer's center frequency. As a result, great care has been taken to use the same cable lengths for all calibrations to ensure that the spectral content of the excitation pulses remains constant. The cable lengths used in NIST calibrations are indicated on the appropriate setups (Figs. 3 and 11.) These lengths, when used in conjunction with the current calibration instrumentation, allow for a tuned center frequency of $5.0 \mathrm{MHz}$.

\section{RC Circuit/Digital Voltmeter}

The positive peak amplitude of the detected ultrasonic pulse of interest from the M90 detector unit is displayed on a digital voltmeter (DVM). This signal is filtered by an $\mathrm{RC}$ circuit possessing a time constant of $0.1 \mathrm{~s}$, which reduces the effect of spurious noise on the voltage readings by time averaging. This filtering improves the stability of the signal reading on the DVM. Due to the long time constant of the circuit, any signal maximizing (while aligning or normalizing the transducer for example) is usually done by observing the signal on the M90 screen, and not by reading the DVM.

\section{Calibration Procedures}

\section{Preliminary Settings}

After the system's excitation pulse and linearity have been checked the calibration can be performed. The following steps are taken for both Area-Amplitude (A-A) and Distance-Amplitude (D-A) block calibrations. Appendix II contains sample dataacquisition forms which show the detailed steps of each type of calibration.

All instrumentation is turned on at least one hour before data is taken, in order to allow for adequate instrument warm-up and stable voltage readings. Before being placed in the tanks, all blocks are visually inspected, and any grease or oil removed from their front surfaces. Nicks, scratches, rust, etc. which are on the front surfaces are noted for each of the blocks, since these may affect the ultrasonic response of the block. This includes any surfaces not appearing to meet the surface roughness criteria in section 10.2 of E127-92a [1]. Finally, the hole plugs on the bottom of each block are inspected to make sure that they appear to be securely sealed and free of corrosion.

As shown in Fig. 2, blocks of varying metal-path-distance are placed in the water on large aluminum steps. This keeps the blocks' front-surfaces at the same height, thereby minimizing the need for adjusting the transducer-to-target distance during the calibration. Once submerged the blocks' entry surfaces are lightly brushed to remove air bubbles which might otherwise interfere with the ultrasonic beam and therefore affect the calibration measurement. Back-lighting through the tank's transparent walls provides a means of easily detecting these air bubbles. 
A $88.9 \mathrm{~mm}(3.5 \mathrm{in})$ long spacer-block is then placed on top of one of the blocks to be calibrated. The transducer is lowered to the top of this spacer-block, which is subsequently removed. The transducer is angulated for normalization to the front-surface of the calibration block and is considered to be normal to the front-surface when a maximum-amplitude front-surface-reflection is detected. The time position of the reflected pulse is then marked on the display of the M90 Reflectoscope. This reference point is used when repositioning the transducer in order to keep the correct and constant water path for all blocks.

\section{Distance-Amplitude (D-A) Sets}

The system sensitivity is set using a master 5-0050 aluminum reference block, designated Ultrasonic Reference Block-1 (URB-1). After beam normalization to the block's front surface, the transducer is moved laterally, in a transverse plane, until a maximum-amplitude reflection from this block's FBH is detected. The system gain is then adjusted until the reflection amplitude is $80 \%$ of full-scale. In this procedure, we note that a master reference block is used instead of the appropriately sized steel balls which are called for in E127-92a. ${ }^{5}$ After setting the initial sensitivity, a gain change which depends on the hole size of the blocks may be needed. Gain settings for the respective hole sizes are determined by their relative FBH areas. Thus, for a number 3 size hole D-A set the gain would be increased by a factor of (25/9), while for a number 8 size hole D-A set the gain would be decreased by a factor of (25/64) compared with a No. 5 hole set. Previous research at NIST has shown that these procedural differences yield more precise and meaningful reference block calibration data, in consonance with E127-92a [6]. In addition, the gain is increased by $8.2 \mathrm{~dB}$ (31 to $80 \% \mathrm{FS}$ ) halfway through a D-A set, in order to obtain an adequate scope display and remain in the system linearity range for the echo responses from the longer metal-path blocks. All gain changes are made in the following manner, where a $31 \%$ to $80 \% \mathrm{FS}$ gain increase is used as an example: The transducer is manipulated laterally until the peak amplitude of any appropriate reflection, usually that from a FBH, decreases to 31 \% FS. The gain controls on the M90 are then adjusted until the peak amplitude of this signal reads $80 \% \mathrm{FS}$. The peak amplitude during this gain adjustment is read on the DVM. Throughout this document, including Appendix II, gain changes are expressed in terms of $\mathrm{dB}$. These are simply unit conversions from the actual \% FS changes used in the gain adjustments. The actual labeled gain values indicated on the M90 are not used for these gain adjustments.

A check-standard (CS) block is measured for each gain setting, to verify that the appropriate gain changes have been made correctly. These check-standard blocks are also used as a means for determining the overall uncertainty of the measurement system, as discussed below. The physical characteristics of the CS blocks are given in Table 1.

\footnotetext{
${ }^{5}$ The appropriately sized steel balls called for in ASTM-E127-92a are measured after setting systemsensitivity on URB-1. These values can then be used by the customer as a reference value. Care must be taken when using the ratio of these values as a "NIST-to-E127 conversion factor," since the different target geometries have different scattering characteristics. These include differences in the spectral content of the reflected pulses and thus differences in system linearity for the distinct targets. In addition, detailed experiments at NIST show that better accuracy is obtained with URB-1 than with steel balls [7].
} 
During the calibration, the maximum echo-amplitude from each block's FBH is read and recorded. The entire measurement scheme is done three times for each block in the set. These three independent measurements yield an average and a check on procedural repeatability for each block. A large variation for a particular block may be an indication that one trial measurement was done incorrectly, and that additional measurements are necessary. The block-response value reported to the customer is the average value of these three trials.

\section{Area-Amplitude (A-A) Sets}

For Area-Amplitude sets, the system-sensitivity is set on the largest-hole block (typically 8-0300) in the set. The echo-amplitude from the FBH of this block is set to $100 \%$ of the full-scale linearity of the system. Each of the smaller-hole blocks are then read in turn, making gain changes of $8.2 \mathrm{~dB}$ after reading the No. 2 and 3 blocks in order to keep the signal in the system's linearity range. As for D-A sets, three independent measurements are made of each block in the set. After all eight A-A blocks (a complete set) have been measured, the 3-0300, 5-0300, and 8-0300 blocks are measured again, using the D-A methodology, as shown in the A-A data-sheet in Appendix II. This is done to determine whether the absolute response of these blocks is correct, as stated in section 11.8 of E127-92a [1].

\section{Calibration Report Contents}

After the measurements are completed, NIST provides a written report to the customer, summarizing the calibration results. A sample calibration report is included in Appendix III of this document. The typical calibration report will include the reduced ultrasonic data in tabular and graphical form, a statement of block acceptance/rejection with respect to the criteria set forth in E127-92a, and a statement regarding the NIST calibration system standard uncertainties.

\section{NIST Ultrasonic Calibration Databases}

The NIST Ultrasonics Group has maintained a database of all calibrations performed since the mid-1970's. In addition, CS data since that time has also been recorded as a means of assessing the measurement uncertainty associated with this calibration.

\section{Calibration Database}

Figure 13 shows a comparison of the NIST calibration database, which includes all calibrated aluminum reference block values, with the minimum and maximum limits prescribed by E127-92a, for metal paths from $12.7 \mathrm{~mm}(0.5 \mathrm{in})$ to $152.4 \mathrm{~mm}(6.0 \mathrm{in})$ and for No. 3, 5, and 8 hole sizes. The average value for each metal-path in the database is indicated $(\bullet)$, along with their \pm two standard deviation $(2 \sigma)$ ranges for all blocks with this metal-path, to indicate their $95 \%$ confidence intervals. The minimum and maximum limits specified in E127 are also indicated (-). For all but the 0575 blocks, the average values from the NIST database fall within the specifications called for by E127-92a. For the larger metal paths there is a trend of the NIST average values to lie closer to the minimum 
E127-92a values. Table III lists the average and standard deviation of all aluminum reference blocks calibrated by NIST, for each metal path. The number of blocks calibrated for each hole size is also indicated. It is worth noting that the large number of $44.5 \mathrm{~mm}(1.75 \mathrm{in})$ and $57.2 \mathrm{~mm}(2.25 \mathrm{in})$ metal path blocks is artificially large, since these blocks are measured twice in each D-A calibration.

The ASTM committee E-07-06, which is responsible for maintaining the E127-92a document, is currently examining the possibility of using the empirical NIST database for establishing new E127-92a recommended values. If this is to be done a fit of the NIST values may be used. Here we fit the average NIST values to an empirical relationship which was previously found by Chwirut to give the best fit for this type of data-set [7].

That empirical relationship is of the following form:

$$
y(x)=\frac{e^{-a x}}{(a+b x)^{2}}
$$

where $x$ is the material path length and $y(x)$ is the echo-amplitude from the FBH. This function's form has a sound theoretical justification, since the $e^{-a x}$ term takes into account the material attenuation $\alpha$, and the $(a+b x)^{2}$ term is the predicted relation for the reflection amplitude from a disc residing in the far-field of the sound beam [7]. The coefficient $\alpha$ is very small for $5 \mathrm{MHz}$ ultrasound in aluminum, while the $\mathrm{a}$ and $\mathrm{b}$ coefficients depend on the transducer characteristics, the water pathlength, transmission and reflection coefficients, sound velocities of the coupling fluid and material, etc. Using our database and a least-squares optimization algorithm [8] we have calculated numerical values for these coefficients. These are presented in Table II. These values describe the NIST aluminum block calibration data, using LS-4 at a water path of $88.9 \mathrm{~mm}$ (3.5 in). Figure 14 shows the NIST average values for each metal-path, and a plot of equation (1) using the calculated values of the three coefficients. The calculated attenuation coefficient $\alpha=0.047 \mathrm{~dB} / \mathrm{cm}(0.0138 \mathrm{~Np} / \mathrm{in})$ is compared with the value $\alpha=0.02 \mathrm{~dB} / \mathrm{cm}$ for $5 \mathrm{MHz}$, as presented by McMaster for AL17ST (0.13 mm grain size) [9].

\section{Check-Standard Database}

Figures 15-20 show plots of the check-standard values measured from 1976 to present. The raw data $(\circ)$ and $\pm 2 \sigma(---)$ values are indicated. Note that each point is the average of the three measurements taken for each calibration. The $\pm 2 \sigma$ values represent the expanded measurement uncertainties of the calibration system, with $\sigma$ representing the combined standard uncertainty [10]. The measurement uncertainty of a measured block value then depends on the particular block's metal-path distance and hole size, as indicated in Table 1, since different check-standards are used with different-sized blocks.

\section{Conclusion}

Here, we have summarized the NIST calibration of ASTM E127-type ultrasonic aluminum reference blocks. The equipment used in the calibration, and the methods used for maintaining the equipment characteristics have been described. We have also briefly outlined the calibration procedures themselves, and have given an overview of the NIST 
calibration database which contains all No. 3, 5, and 8 hole-size aluminum blocks calibrated by NIST since 1976.

\section{Acknowledgments}

The authors would like to thank Dr. David Gilsinn for his help with the numerical least-squares algorithm. We would also like to acknowledge the many NIST and ASTM E-07-06 readers of the draft copy of this document, including Dr. Donald Eitzen, Mr. Bill Crupe, Mr. Howard Van Valkenburg (New Fairfield, CT.), and Mr. Jerry Green (Alcoa Aluminum Co., Alcoa Center, PA.). All of their comments and suggestions for this document are greatly appreciated. 


\section{$\underline{\text { References }}$}

[1] Standard Practice for Fabricating and Checking Aluminum Alloy Ultrasonic Standard Reference Blocks, E127-92a, in Annual Book of ASTM Standards, Philadelphia, Pennsylvania: American Society for Testing and Materials; 1992.

[2] Chwirut, D.J., Sushinsky, G.F., and Eitzen, D.G., Procedures for the Calibration of ASTM E 127-Type Ultrasonic Reference Blocks. Nat. Bur. Stand. (U.S.) Tech. Note 924; (September 1976).

[3] Unpublished NIST Data.

[4] Chwirut, D.J., and Boswell, G.D., The Evaluation of Search Units used for Ultrasonic Reference Block Calibrations. Nat. Bur. Stand. (U.S.) Internal Report NBSIR 78-1454; (February 1978).

[5] Eastern NDT Inc., 200 N. Main Street, Suite 212, Hopewell, Virginia 23860

[6] Sushinsky, G.F., et al., Improved Ultrasonic Standard Reference Blocks. NBSIR 76-984; (November 1976).

[7] Chwirut, D.J., Recent Improvements to the ASTM-type Ultrasonic Reference Block System. NBSIR 79-1742; (April 1979).

[8] Atkinson, K.E., An Introduction to Numerical Analysis, John Wiley and Sons, NY (1978).

[9] McMaster, R.C., Nondestructive Testing Handbook, Roland Press Company, NY (1959).

[10] Taylor, B.N., and Kuyatt, C.E., Guidelines for Evaluating and Expressing the Uncertainty of NIST Measurement Results. NIST Technical Note 1297 (January 1993). 
THIS PAGE INTENTIONALLY LEFT BLANK 


\section{Appendix I: Procedures for Requesting Ultrasonic Reference Block Calibrations}

Interested parties should call the technical contact listed below, before sending block sets to be calibrated. The technical contact will inform the customer of the cost of the calibration, and any other pertinent information. The customer should then send a company purchase order and the block set(s) to the address below. The purchase order should preferably be sent prior to the block set(s) and should clearly state the type of calibration to be performed, the cost, purchase order number, the bill-to office, and the name, address, and phone number of the person responsible for the block set(s). No calibrations can be performed until NIST has received and processed this purchase order. Therefore, the turn-around time for ultrasonic reference block calibrations can be shortened if NIST receives the purchase order before the block sets. Normally, customers can expect a four week turn-around time, although this time can be reduced in special circumstances. A table listing the various reference block calibration services offered by the NIST Ultrasonics Group is presented on the next page.

Technical Contact:

Mr. John A. Slotwinski

Building 233 / Room A147

N.I.S.T.

Gaithersburg, Maryland 20899-0001

(301) $975-2171$ 
NIST Ultrasonics Group Reference Block Calibration Services

\begin{tabular}{|c|l|r|}
\hline Test No. & \multicolumn{1}{|c|}{ Description of Services } & Fee (S) \\
\hline $26030 \mathrm{~S}$ & $\begin{array}{l}\text { Special Test of Area Amplitude Aluminum } \\
\text { Reference Blocks - Set of Eight Blocks }\end{array}$ & At Cost \\
\hline $26040 \mathrm{~S}$ & $\begin{array}{l}\text { Special Test of Area Amplitude Titanium or } \\
\text { Steel Ultrasonic Reference Blocks - Set of } \\
\text { Eight Blocks }\end{array}$ & 1130 \\
\hline $26050 \mathrm{~S}$ & $\begin{array}{l}\text { Special Test of Distance Amplitude } \\
\text { Aluminum Reference Blocks - Set of } \\
\text { Fifteen Blocks }\end{array}$ & At Cost \\
\hline $26060 \mathrm{~S}$ & $\begin{array}{l}\text { Special Test of Distance Amplitude } \\
\text { Titanium or Steel Ultrasonic Reference } \\
\text { Blocks - Set of Fifteen Blocks }\end{array}$ & $\begin{array}{l}\text { At Cost } \\
\text { Special Test of Distance/Area Amplitude } \\
\text { (Basic Set) Aluminum, Titanium or Steel } \\
\text { Ultrasonic Reference Blocks - Set of Eight } \\
\text { Blocks }\end{array}$ \\
\hline
\end{tabular}

These prices are subject to change. Consult the latest edition of the NIST Calibration Services Users Guide and Fee Schedule (NIST Special Publication 250, January 1993), or contact the technical contact listed on the previous page for more information. 
Appendix II: Data-Acquisition Forms used in NIST Calibrations of ASTM E127-type Reference Blocks

COMPANY:

AREA-AMPLTUDE

CAUB. NO.:

$\mathrm{S} / \mathrm{N}$ :

TECHNICIAN:

DATE:

\begin{tabular}{|l|c|c|c|}
\hline BLOCK & Trial I & Trial 2 & Trial 3 \\
\hline $8-0300$ & $100 \%$ & $100 \%$ & $100 \%$ \\
\hline $7-0300$ & & & \\
\hline $6-0300$ & & & \\
\hline $5-0300$ & & & \\
\hline $4-0300$ & & & \\
\hline $3-0300$ & & & \\
\hline INCREASE GAIN 8.2 dB & & & \\
\hline $3-0300$ & & & \\
\hline $2-0200$ & & & \\
\hline INCREASE GAIN 8.2 dB & & & \\
\hline $2-0300$ & & & \\
\hline $1-0300$ & & & \\
\hline URB-1 & $80 \%$ & $80 \%$ & $80 \%$ \\
\hline INCREASE GAIN 8.6 dB & & & \\
\hline INCREASE GAIN 8.2 dB & & & \\
\hline 3.175 mm (1/8 in) BALI & & & \\
\hline CS-2 & & & \\
\hline $3-0300$ & & & \\
\hline URB-1 & $80 \%$ & $80 \%$ & $80 \%$ \\
\hline INCREASE GAIN 8.2 dB & & & \\
\hline 7.938 mm (5/16 in) BALL & & & \\
\hline CS-4 & & & \\
\hline $5-0300$ & & & \\
\hline URB-1 & $31.5 \%$ & $31.5 \%$ & $31.5 \%$ \\
\hline INCREASE GAIN 8.2 dB & & & \\
\hline 17.463 mm (11/16 in) BALL & & & \\
\hline CS-6 & & & \\
\hline $8-0300$ & & & \\
\hline
\end{tabular}


COMPANY:

$\mathrm{S} / \mathrm{N}$ :

DISTANCE-AMPUTUDE

ALUMINUM NO. 3 HOLE

\begin{tabular}{|l|c|c|c|}
\hline BLOCK & Trial I & Trial 2 & Trial 3 \\
\hline URB-1 & $80 \%$ & $80 \%$ & $80 \%$ \\
\hline INCREASE GAIN 8.9 dB & & & \\
\hline $3.175 \mathrm{~mm}(1 / 8 \mathrm{in})$ BALL & & & \\
\hline CS-1 & & & \\
\hline $3-0050$ & & & \\
\hline $3-0063$ & & & \\
\hline $3-0075$ & & & \\
\hline $3-0088$ & & & \\
\hline $3-0100$ & & & \\
\hline $3-0125$ & & & \\
\hline $3-0175$ & & & \\
\hline $3-0225$ & & & \\
\hline INCREASE GAIN 8.2 dB & & & \\
\hline CS-2 & & & \\
\hline $3-0175$ & & & \\
\hline $3-0225$ & & & \\
\hline $3-0275$ & & & \\
\hline $3-0325$ & & & \\
\hline $3-0375$ & & & \\
\hline $3-0425$ & & & \\
\hline $3-0475$ & & & \\
\hline $3-0525$ & & & \\
\hline $3-0575$ & & & \\
\hline
\end{tabular}

CALUB. NO.:

TECHNICIAN:

DATE: 
COMPANY:

$S / N$ :

DISTANCE-AMPUTUDE

ALUMINUM NO. 5 HOLE

\begin{tabular}{|l|c|c|c|}
\hline BLOCK & Trial 1 & Trial 2 & Trial 3 \\
\hline URB-1 & $80 \%$ & $80 \%$ & $80 \%$ \\
\hline $7.938 \mathrm{~mm}(5 / 16 \mathrm{in}) \mathrm{BAL}$ & & & \\
\hline CS-3 & & & \\
\hline $5-0050$ & & & \\
\hline $5-0063$ & & & \\
\hline $5-0075$ & & & \\
\hline $5-0088$ & & & \\
\hline $5-0100$ & & & \\
\hline $5-0125$ & & & \\
\hline $5-0175$ & & & \\
\hline $5-0225$ & & & \\
\hline INCREASE GAIN 8.2 dB & & & \\
\hline CS-4 & & & \\
\hline $5-0175$ & & & \\
\hline $5-0225$ & & & \\
\hline $5-0275$ & & & \\
\hline $5-0325$ & & & \\
\hline $5-0375$ & & & \\
\hline $5-0425$ & & & \\
\hline $5-0475$ & & & \\
\hline $5-0525$ & & & \\
\hline $5-0575$ & & & \\
\hline
\end{tabular}

CAUB. NO:

TECHNICIAN:

DATE: 
COMPANY:

$\mathrm{S} / \mathrm{N}$ :

DISTANCE-AMPUTUDE

ALUMINUM NO. 8 HOLE

\begin{tabular}{|l|l|l|l|}
\hline BLOCK & Trial 1 & Trial 2 & Trial 3 \\
\hline URB-1 & $31.3 \%$ & $31.3 \%$ & $31.3 \%$ \\
\hline $17.463 \mathrm{~mm}$ (11/16 in) BALL & & & \\
\hline CS-5 & & & \\
\hline $8-0050$ & & & \\
\hline $8-0063$ & & & \\
\hline $8-0075$ & & & \\
\hline $8-0088$ & & & \\
\hline $8-0100$ & & & \\
\hline $8-0125$ & & & \\
\hline $8-0175$ & & & \\
\hline $8-0225$ & & & \\
\hline INCREASE GAIN 8.2 dB & & & \\
\hline CS-6 & & & \\
\hline $8-0175$ & & & \\
\hline $8-0225$ & & & \\
\hline $8-0275$ & & & \\
\hline $8-0325$ & & & \\
\hline $8-0375$ & & & \\
\hline $8-0425$ & & & \\
\hline $8-0475$ & & & \\
\hline $8-0525$ & & & \\
\hline $8-0575$ & & & \\
\hline
\end{tabular}

CALB. NO.:

TECHNICIAN:

DATE: 


\title{
Appendix III: Sample Distance-Amplitude Calibration Report
}

TN-000000-93

J.A. Slotwinski/bam

September 23, 1993

\author{
U.S. DEPARTMENT OF COMMERCE \\ NATIONAL INSTITUTE OF STANDARDS AND TECHNOLOGY \\ GAITHERSBURG, MD 20899 \\ REPORT OF CALIBRATION
}

\author{
OF \\ Requested by \\ Any Company \\ P.O. Box 0001 \\ Anywhere, USA
}

One Set of Aluminum No. 5 D-A Blocks

Block Manufacturer S.N. 0001

The set of fifteen aluminum reference blocks was calibrated according to the procedures of the NIST document entitled "NIST Calibration of ASTM E127-Type Ultrasonic Reference Blocks." In these procedures, the ultrasonic system sensitivity is based on the echo amplitude from the National Institute of Standards and Technology (NIST) master flat-bottom-hole (FBH) block of size 5-0050, rather than the steel reference balls called for in ASTM E127-92a. Gain settings for the respective hole sizes are in turn determined by their relative FBH areas. Research at NIST has indicated that these procedural differences yield more precise and meaningful reference block calibration data in consonance with ASTM E127-92a. (Using these procedures, the echo amplitude response value of the $7.9 \mathrm{~mm}(5 / 16 \mathrm{in})$ steel ball was $70.1 \% \mathrm{FS}$.)

The calibration results are given in Fig. 1. For each reference block, the percent of full scale (\% FS) average of three readings is graphed and tabulated. Note that the system gain was increased from 31 to $80 \%$ FS, after the first measurement of the $57.2 \mathrm{~mm}(2.25$ in) metal-path block. After taking into account NIST procedural differences and the combined standard uncertainty of the system, the echo amplitude responses of all blocks except 5-0575 fell within the range of the E127-92a established values. The 5-0575 block was slightly lower than the established values of E127-92a. 
We also report NIST system combined standard uncertainties using a NIST master set of aluminum FBH blocks as check standards. These (total) system combined standard uncertainty values are determined for each receiver gain setting that is used for each range of blocks. They represent random and some systematic errors associated with the NIST system. (We note that other systematic errors or changes may produce differences greater than the uncertainties reported here.) Based on check standard data accumulated since 1976 , the NIST system expanded uncertainty for the short blocks [12.7 mm to $57.2 \mathrm{~mm}$ $\left(0.50\right.$ to 2.25 in)] is $\left(\frac{2.2}{64.4}\right)$ of the block response readings, and for the long blocks [ 44.5 $\mathrm{mm}$ to $152.4 \mathrm{~mm}(1.75$ to $6.00 \mathrm{in})]$ after a gain increase is $\left(\frac{2.4}{29.4}\right)$ of the block response readings. (The stated expanded uncertainty is twice the combined uncertainty ( $2 \sigma$ value), corresponding to a $95 \%$ confidence interval.)

We note that the values reported herein apply to the blocks calibrated only with the ultrasonic system and instrument settings used at NIST. The National Institute of Standards and Technology cannot assure that the customer's blocks will have these same values when measured in the customer's facility on another day. The dependence of the echo amplitude on the particular ultrasonic system used is well documented, and is available from NIST upon request. 


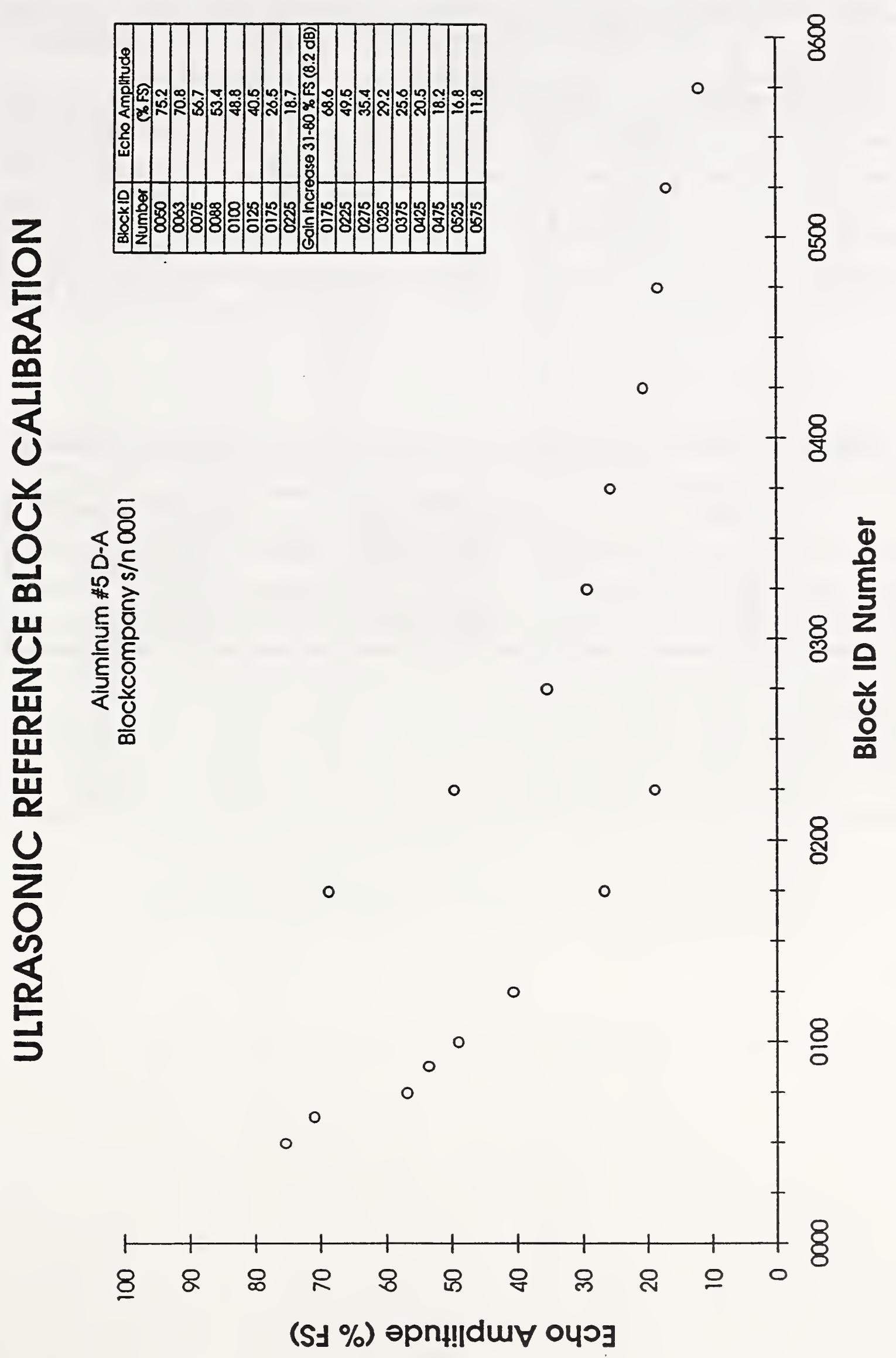


Table I: Dimensional and ultrasonic characteristics of NIST check-standard blocks.

\begin{tabular}{|c|c|c|c|c|}
\hline $\begin{array}{c}\text { Block } \\
\text { Designation }\end{array}$ & Block Size & $\begin{array}{c}\text { Average Echo } \\
\text { Amplitude } \\
(\% \text { FS })\end{array}$ & $\begin{array}{c}2 \sigma \\
(\% \text { FS })\end{array}$ & Applicable to \\
\hline CS-1 & $3-0225$ & 22.9 & 2.4 & short No.3 blocks \\
\hline CS-2 & $3-0175$ & 79.6 & 4.8 & long No. 3 blocks \\
\hline CS-3 & $5-0075$ & 64.4 & 2.2 & short No. 5 blocks \\
\hline CS-4 & $5-0375$ & 29.4 & 2.4 & long No. 5 blocks \\
\hline CS-5 & $8-0175$ & 29.3 & 1.2 & short No. 8 blocks \\
\hline CS-6 & $8-0325$ & 35.6 & 1.4 & long No. 8 blocks \\
\hline
\end{tabular}

Table II: Calculated values of numerical coefficients in Eq. (1), using NIST database.

\begin{tabular}{|c|c|c|}
\hline Coefficient & $\begin{array}{c}\text { Computed Numerical } \\
\text { Value (metric) }\end{array}$ & $\begin{array}{c}\text { Computed Numerical } \\
\text { Value (in-lb) }\end{array}$ \\
\hline$\alpha$ & $0.047 \mathrm{~dB} / \mathrm{cm}$ & $0.0138(\mathrm{~Np} / \mathrm{in})$ \\
\hline $\mathrm{a}$ & $0.0836(-)$ & $0.0836(-)$ \\
\hline $\mathrm{b}$ & $0.023\left(\mathrm{~cm}^{-1}\right)$ & $0.0584\left(\mathrm{in}^{-1}\right)$ \\
\hline
\end{tabular}


Table III: Average, standard deviation, and number of blocks calibrated for each metal path in the NIST database, since 1976.

\begin{tabular}{|c|c|c|c|}
\hline Block ID Number & Average (\% FS) & $\sigma(\%$ FS) & Number of Blocks \\
\hline 0050 & 75.3 & 3.6 & 116 \\
\hline 0063 & 70.3 & 3.5 & 73 \\
\hline 0075 & 61.9 & 3.1 & 115 \\
\hline 0088 & 55.9 & 2.6 & 74 \\
\hline 0100 & 49.6 & 2.3 & 93 \\
\hline 0125 & 40.4 & 1.5 & 75 \\
\hline 0150 & 31.9 & 2.3 & 34 \\
\hline 0175 & 27.8 & 1.5 & 151 \\
\hline 0200 & 23.5 & 2.3 & 29 \\
\hline 0225 & 20.2 & 1.3 & 150 \\
\hline 0250 & 17.7 & 2.1 & 24 \\
\hline 0275 & 15.5 & 1.1 & 95 \\
\hline 0300 & 14.4 & 2.4 & 103 \\
\hline 0325 & 12.3 & 1.0 & 76 \\
\hline 0375 & 10.0 & 0.9 & 79 \\
\hline 0400 & 9.7 & 1.2 & 14 \\
\hline 0425 & 8.2 & 0.9 & 74 \\
\hline 0475 & 7.0 & 0.9 & 74 \\
\hline 0500 & 7.7 & 1.4 & 14 \\
\hline 0525 & 6.2 & 1.0 & 74 \\
\hline 0575 & 5.5 & 0.9 & 73 \\
\hline 0600 & 7.4 & 2.9 & 31 \\
\hline & & & \\
\hline
\end{tabular}




\section{Ultrasonic Wave Entry Surface}

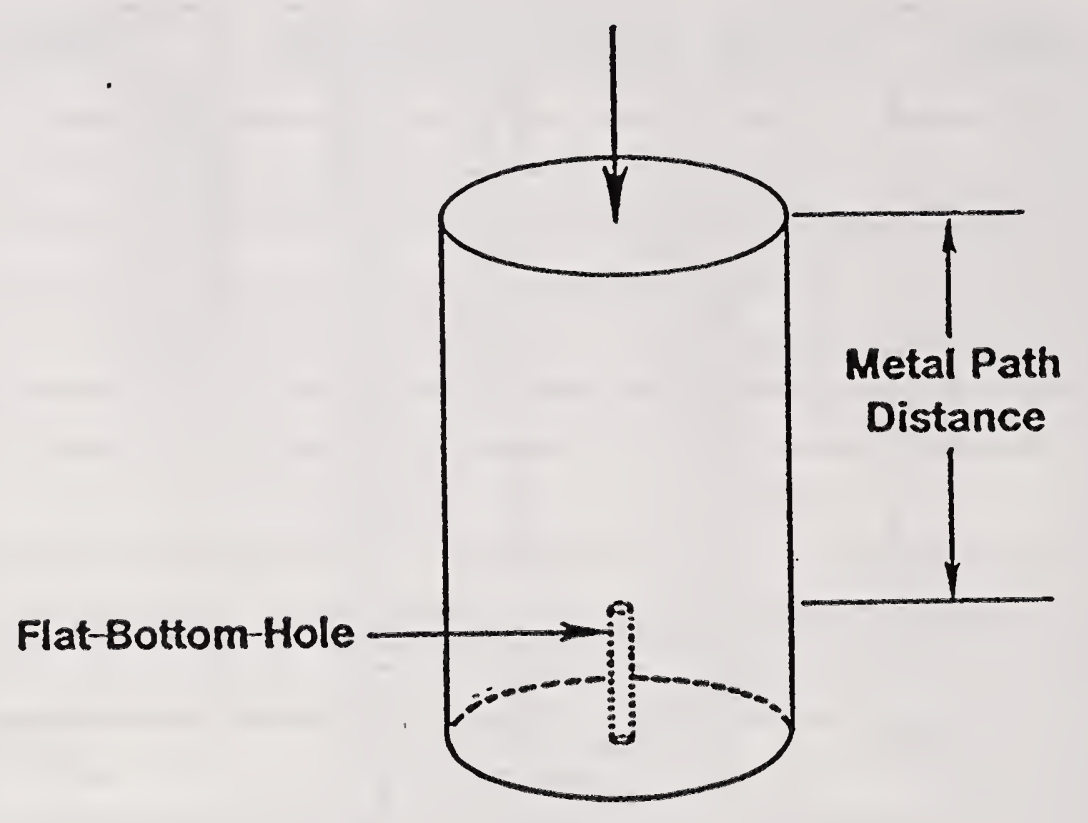

Figure 1: Schematic of generic ASTM E127-92a-type aluminum reference block which shows the position and orientation of the flat-bottom-hole (FBH) relative to the ultrasonic wave entry surface. 


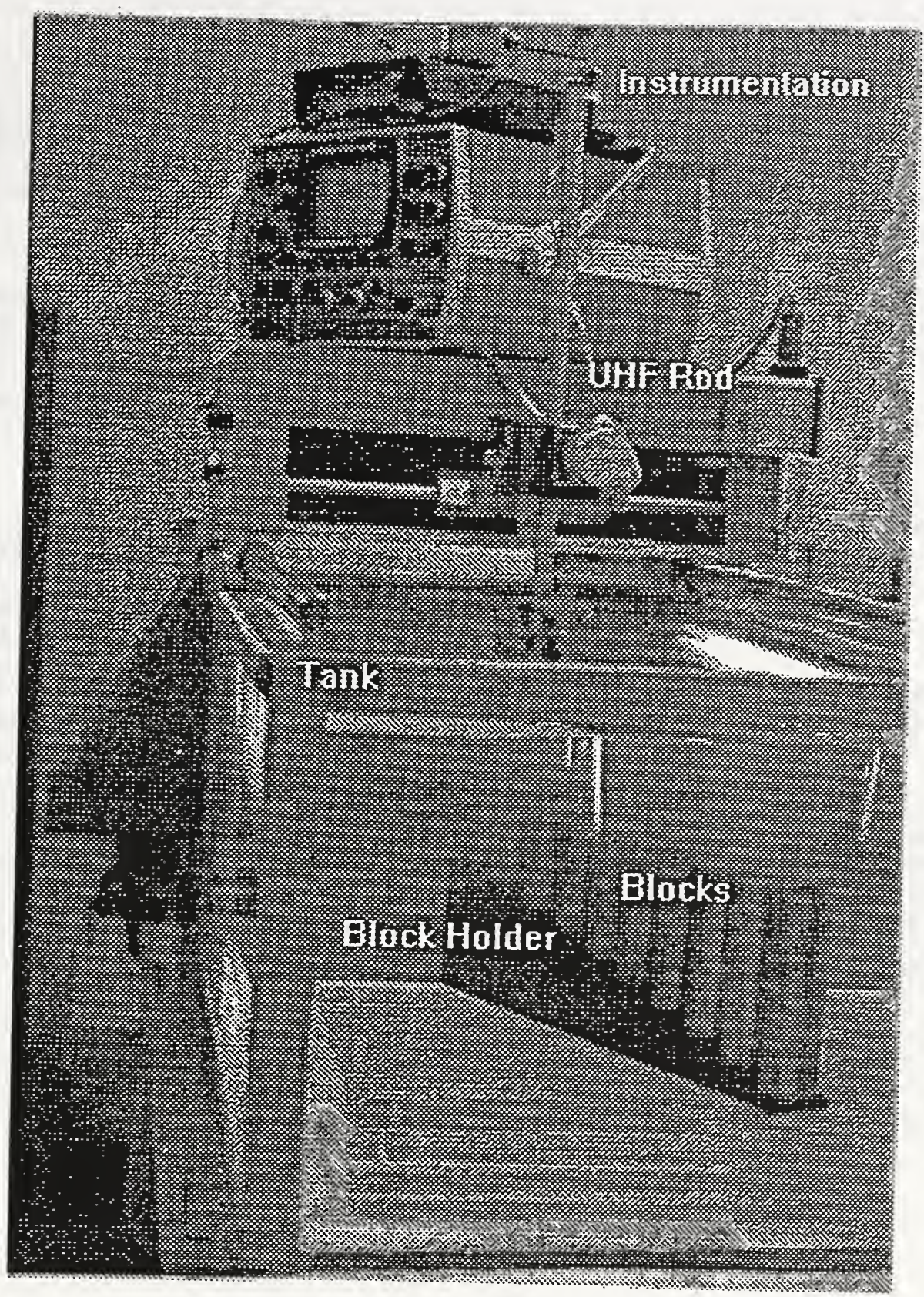

Figure 2: Photograph of ultrasonic calibration system, immersion tank, and block holder. 


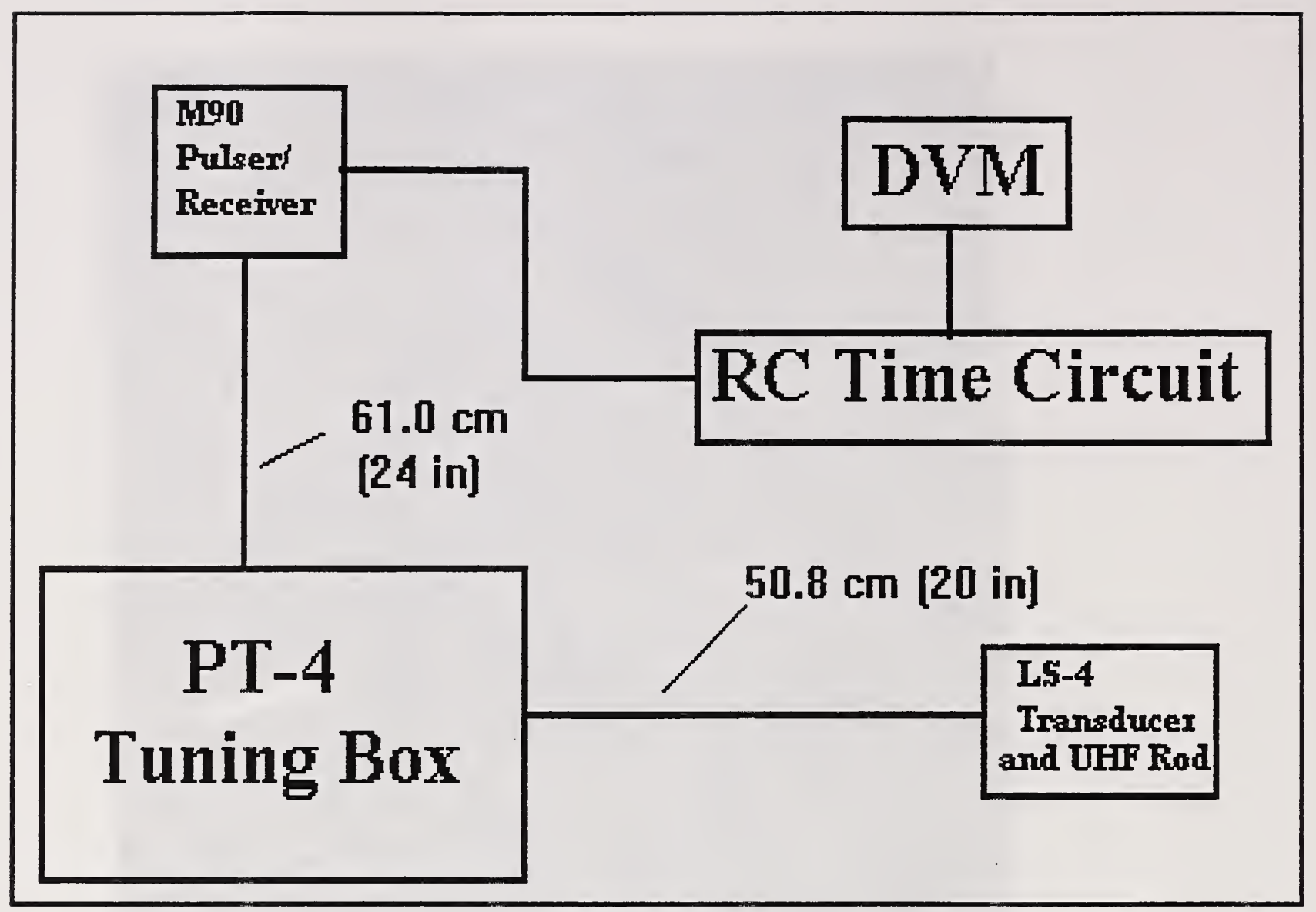

Figure 3: Ultrasonic Instrumentation Setup for calibration of ASTM E127-92a type aluminum reference blocks, with cable lengths indicated. 

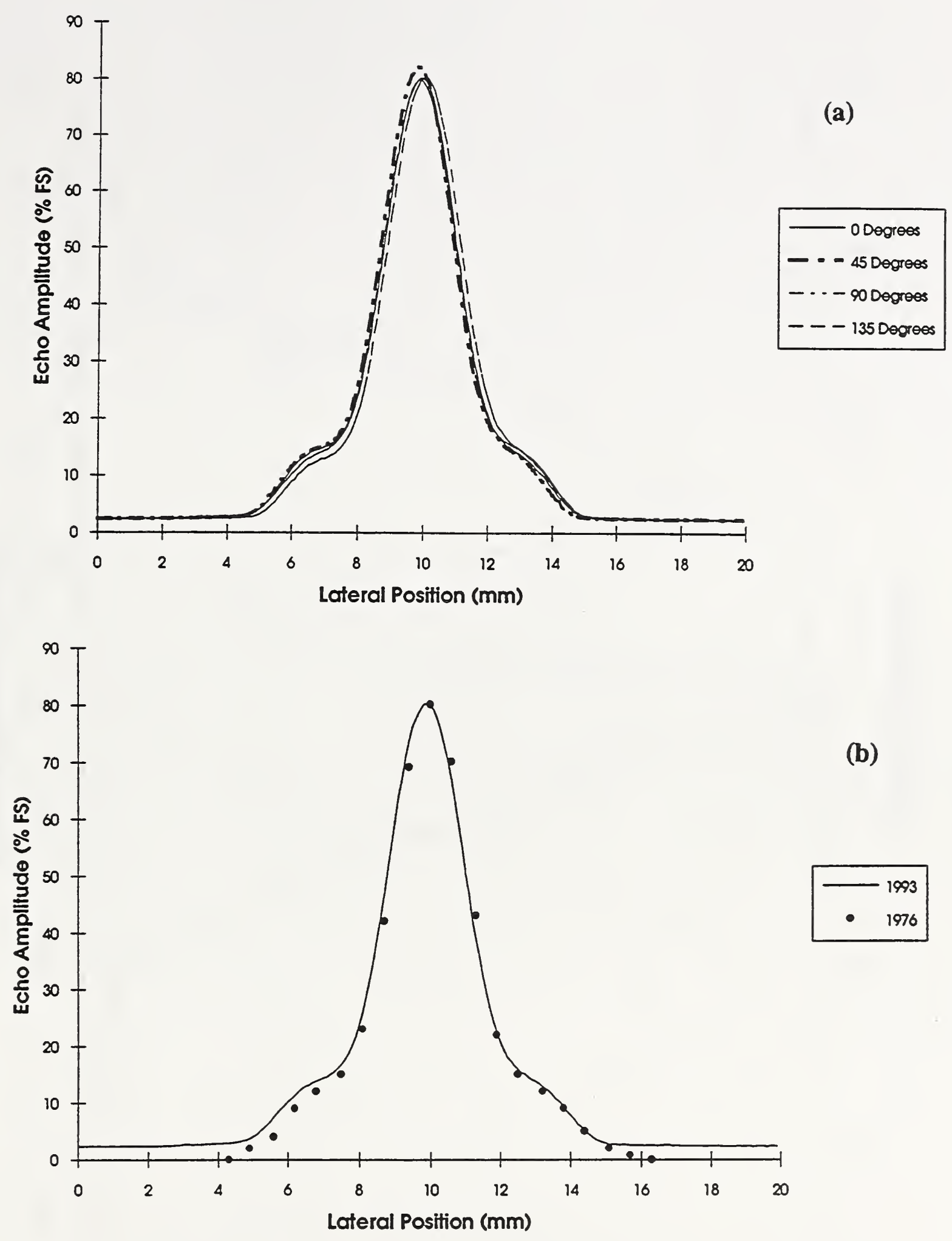

Figure 4: (a) Lateral scans of LS-4 taken using a $12.7 \mathrm{~mm}(0.5 \mathrm{in})$ steel sphere target at $89.9 \mathrm{~mm}$ ( $\mathrm{Y}_{0}^{+}$point) water path distance. The scans are taken at four different rotational orientations of the transducer, which are separated by $45^{\circ}$ of rotation. (b) Comparison of one of the 4a scans with one which was taken by Chwirut [2] in 1976. The good agreement between the 1993 continuous scan data and the 1976 discrete data is one indication of LS-4's stability over time. 


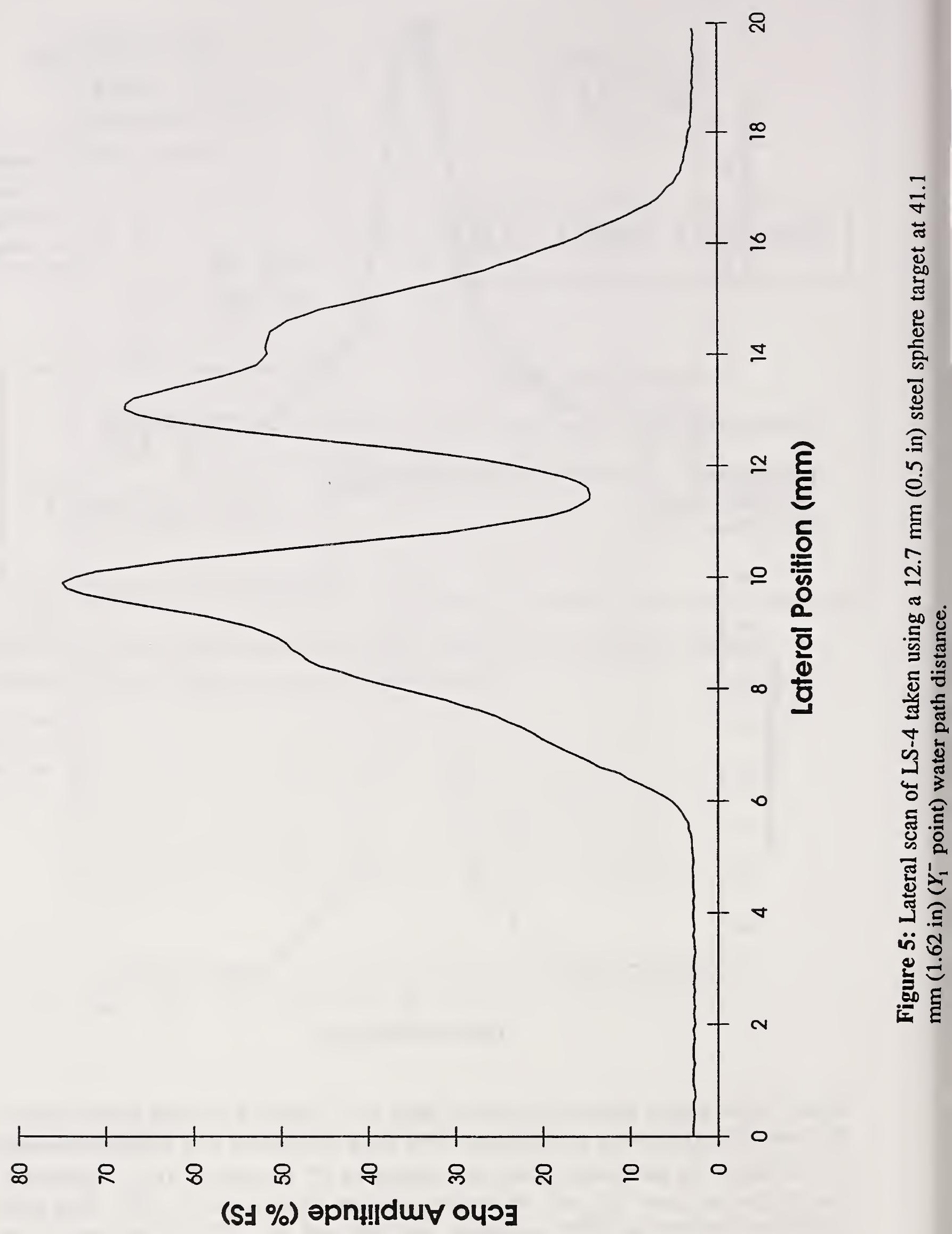




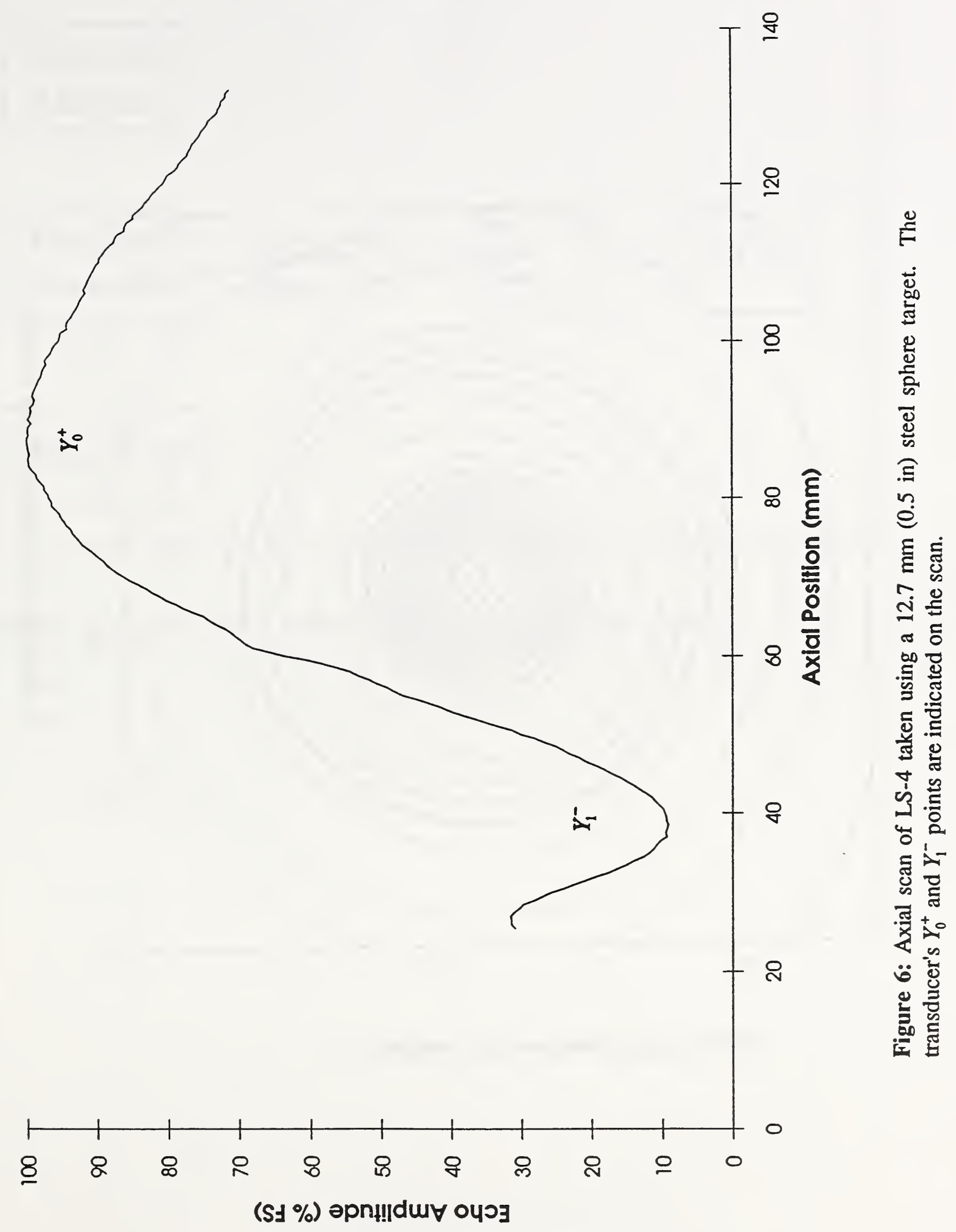



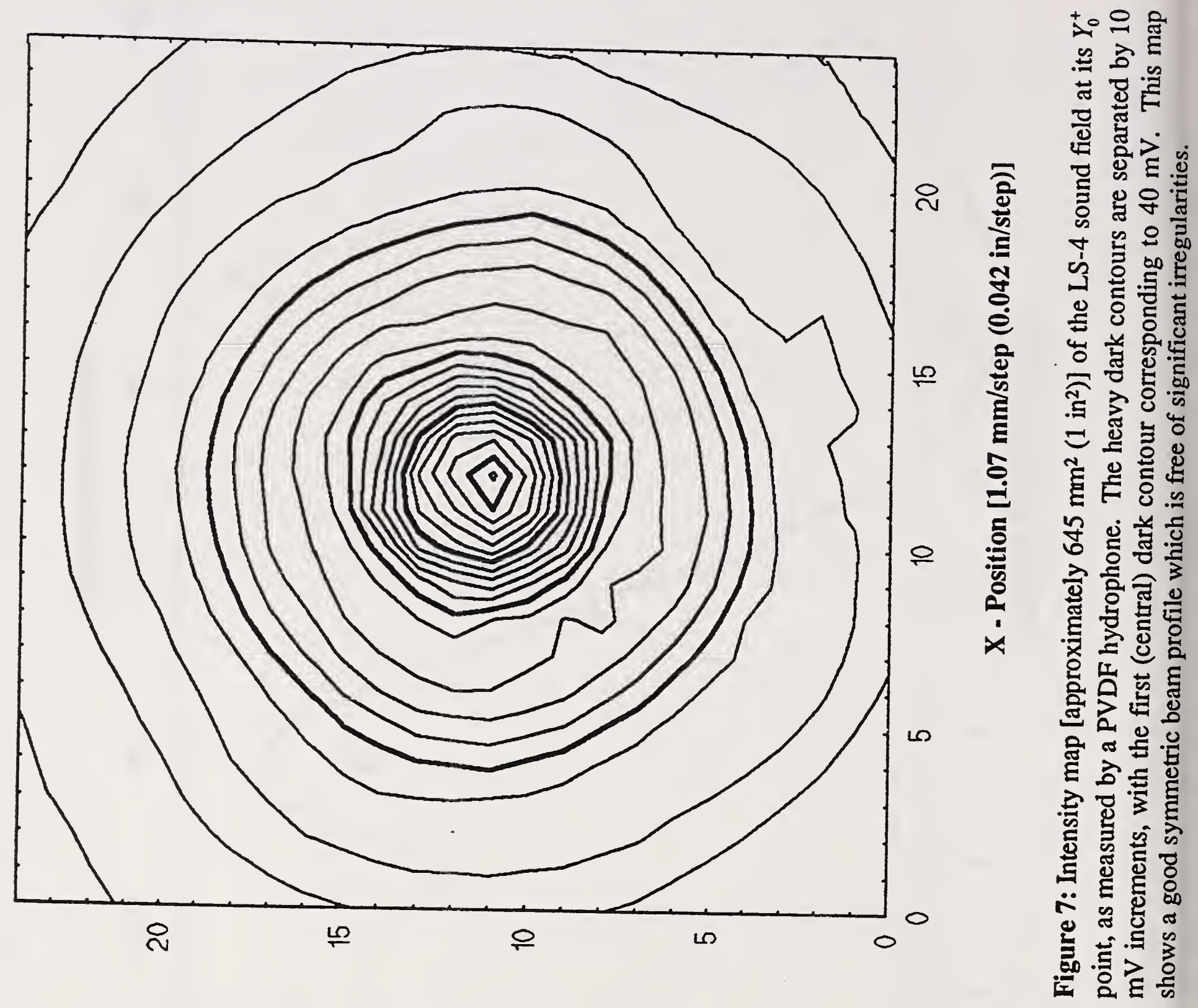

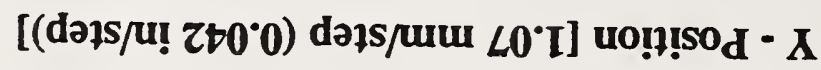




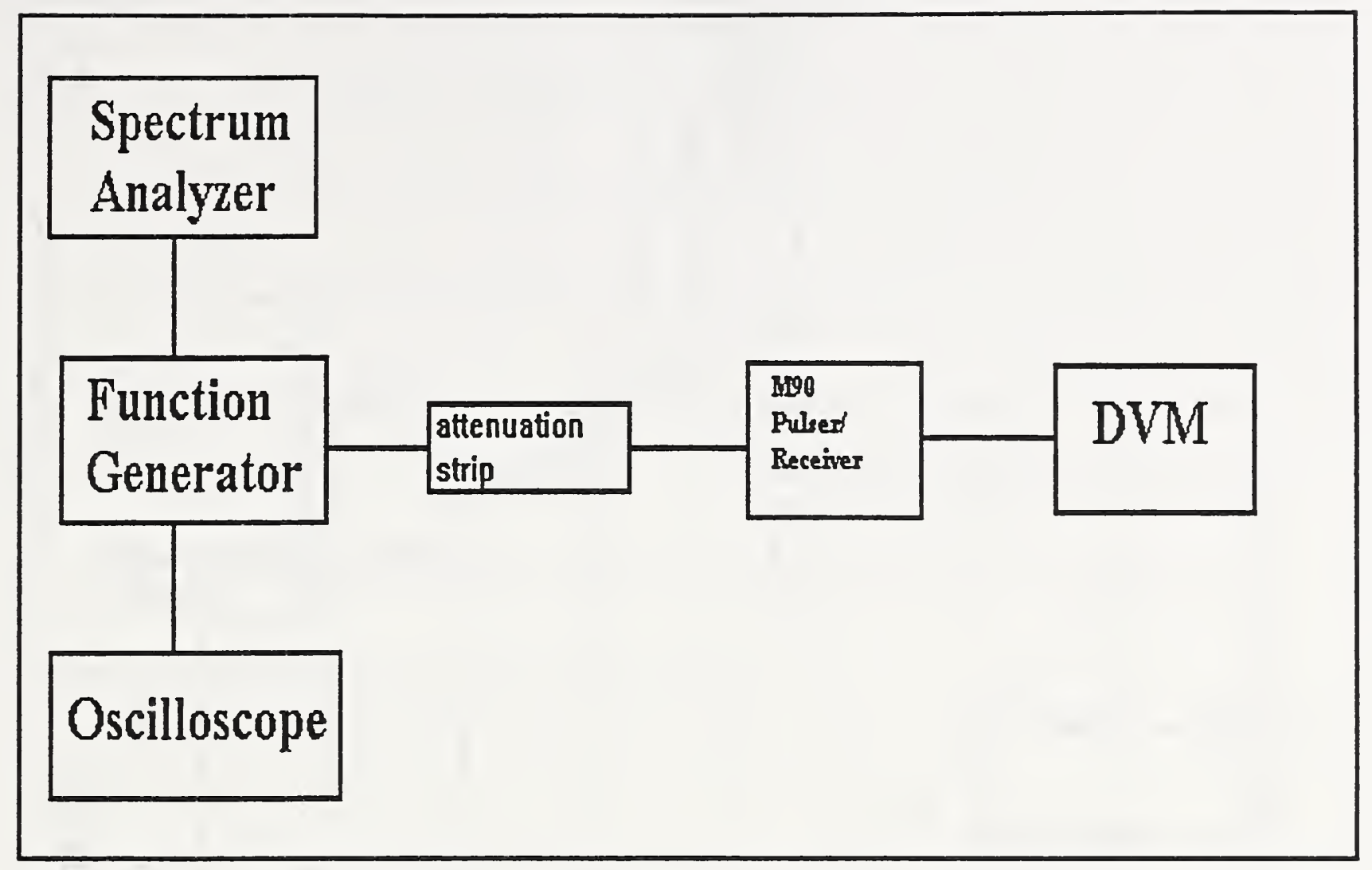

Figure 8: Arrangement used to measure the M90's receiver amplitude linearity. 

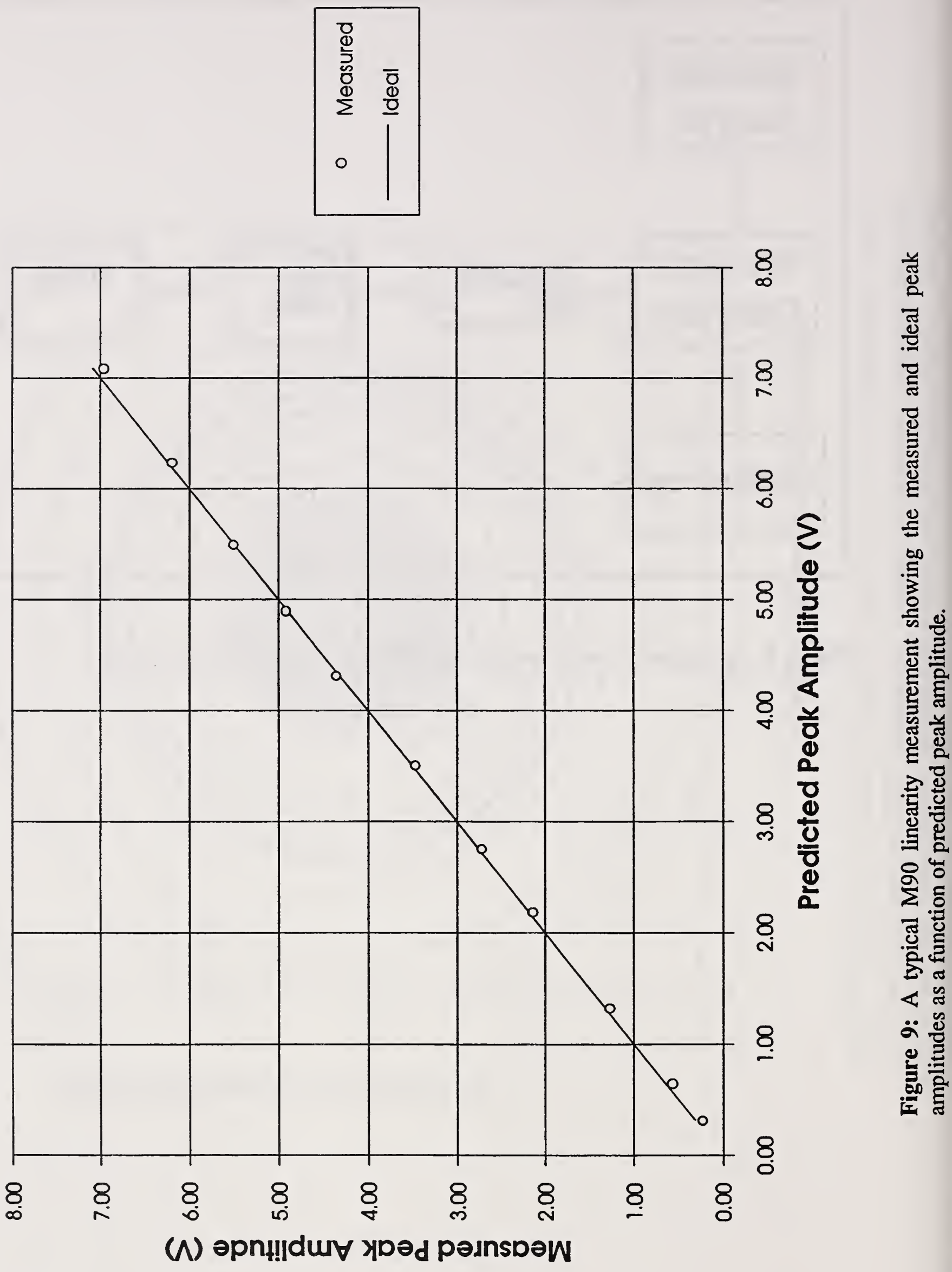


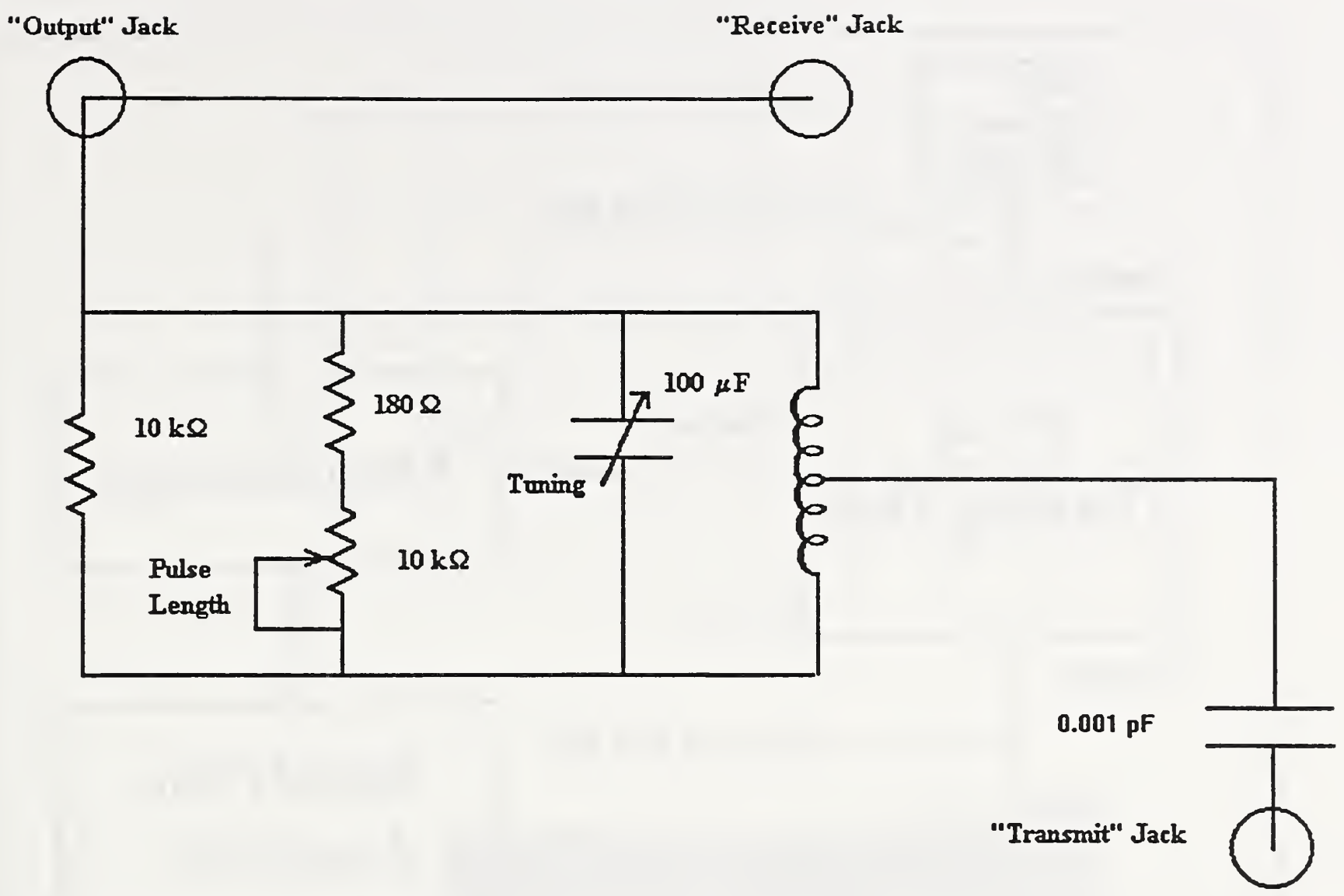

Figure 10: PT-4 tuning circuit schematic. This circuit is used to tune the M90 shockexcitation. 


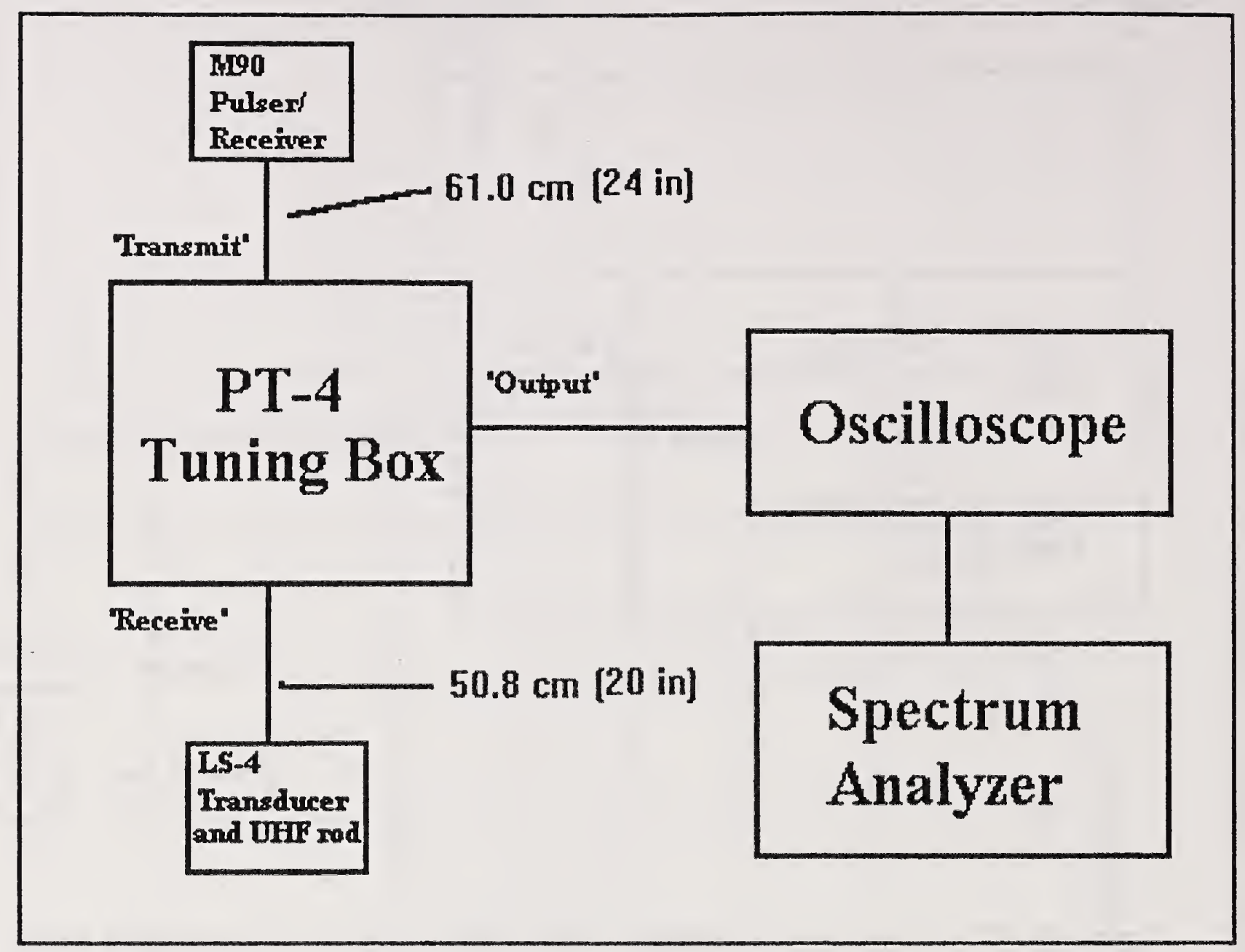

Figure 11: Setup for checking the frequency content of the M90 shock-excitation. 


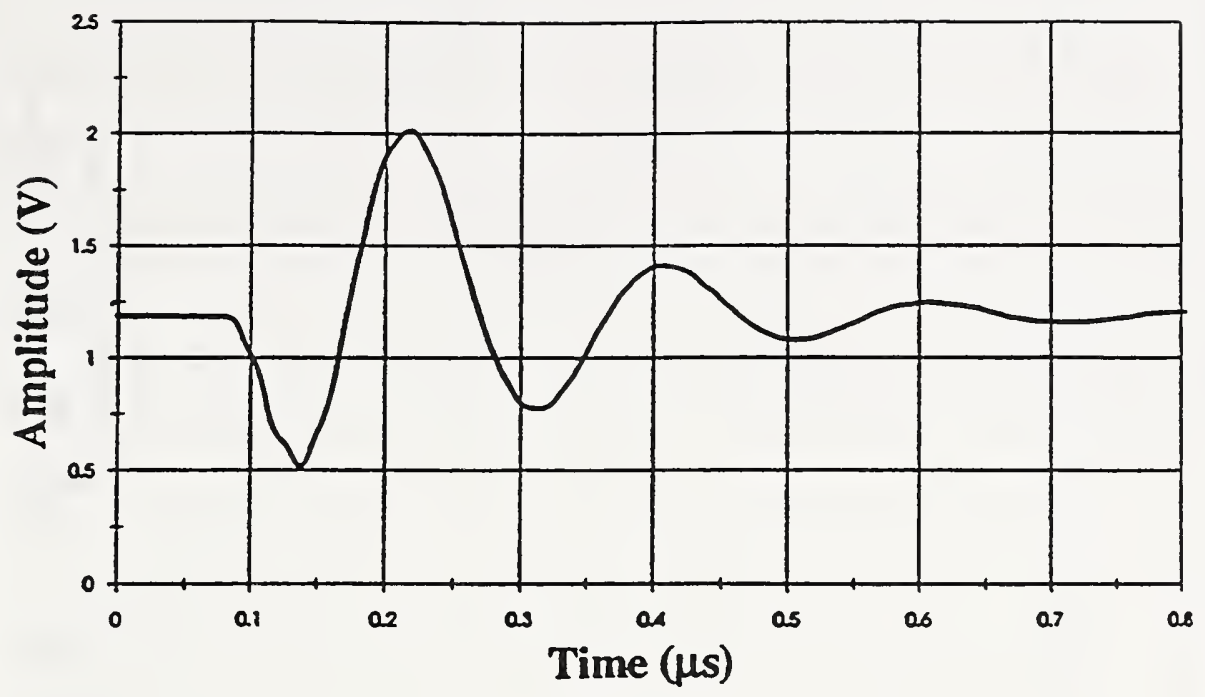

(a)

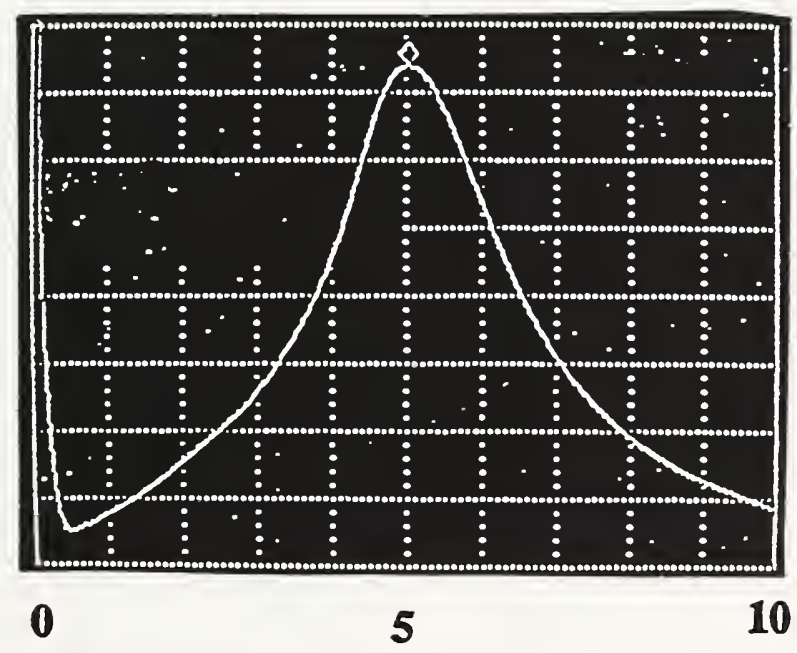

(b)

Frequency (MHz)

Figure 12: (a) Typical shock excitation pulse (tuned) and its (b) corresponding frequency spectrum on a linear vertical scale. 


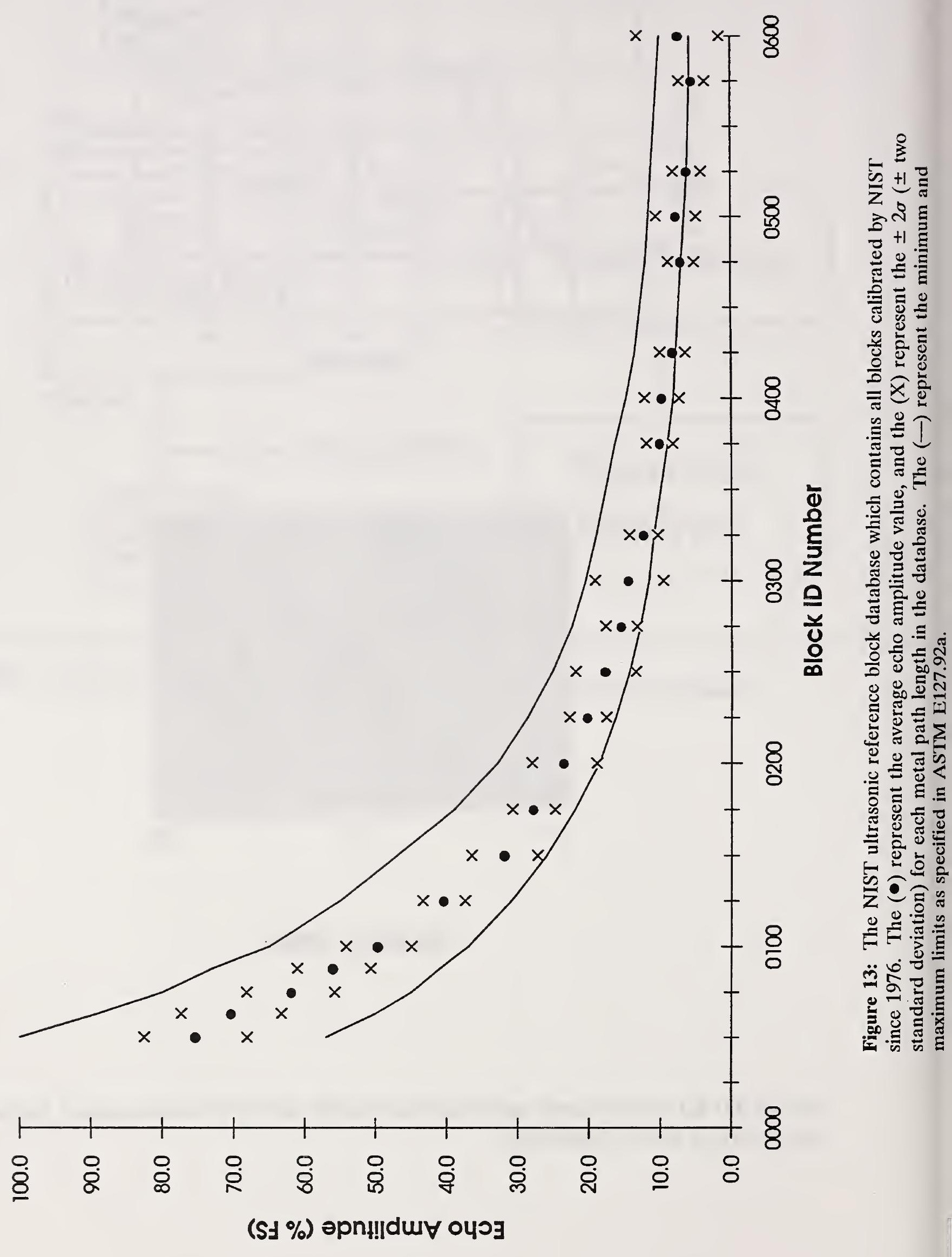




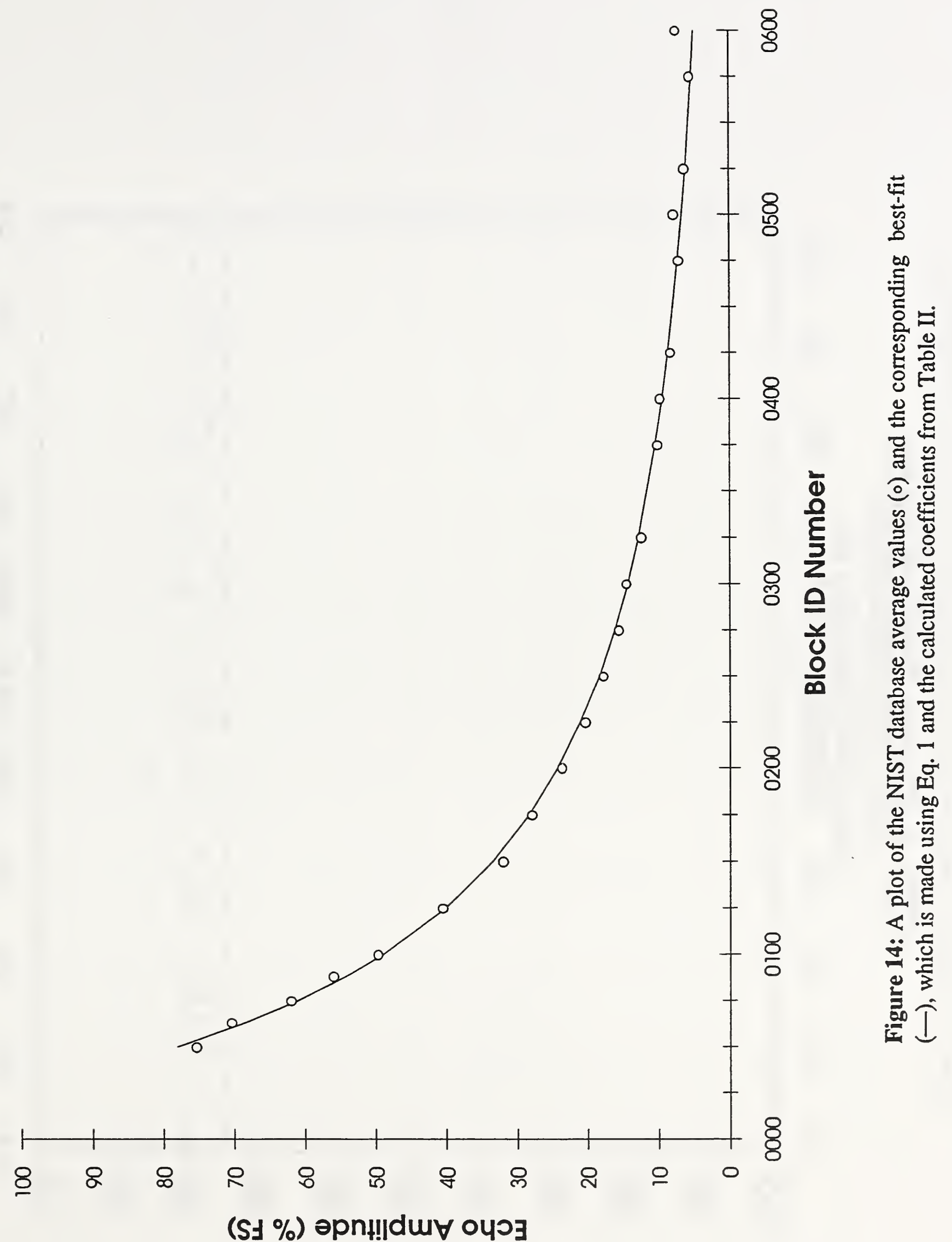




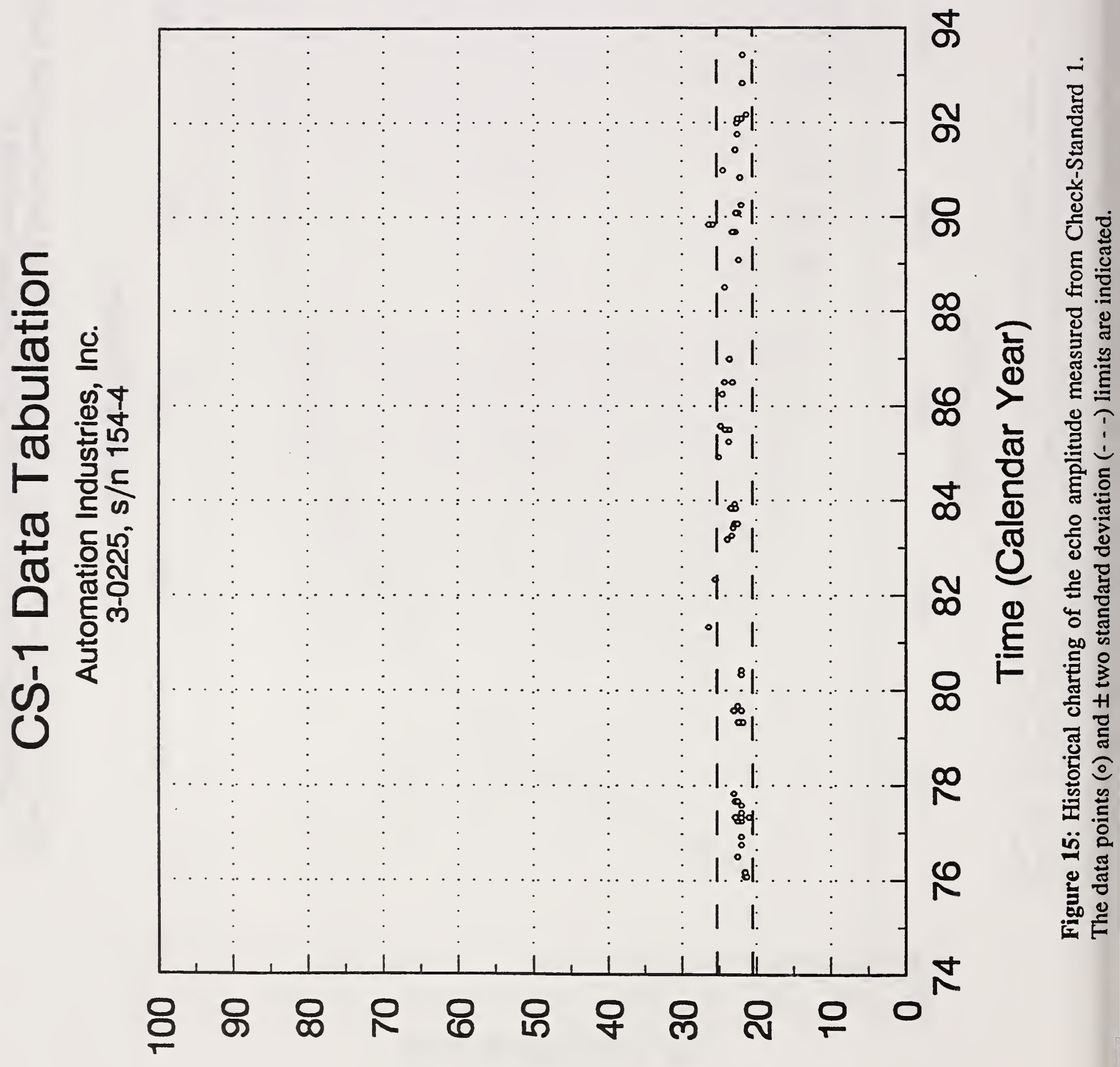

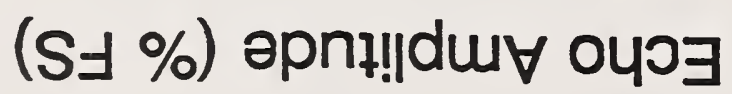




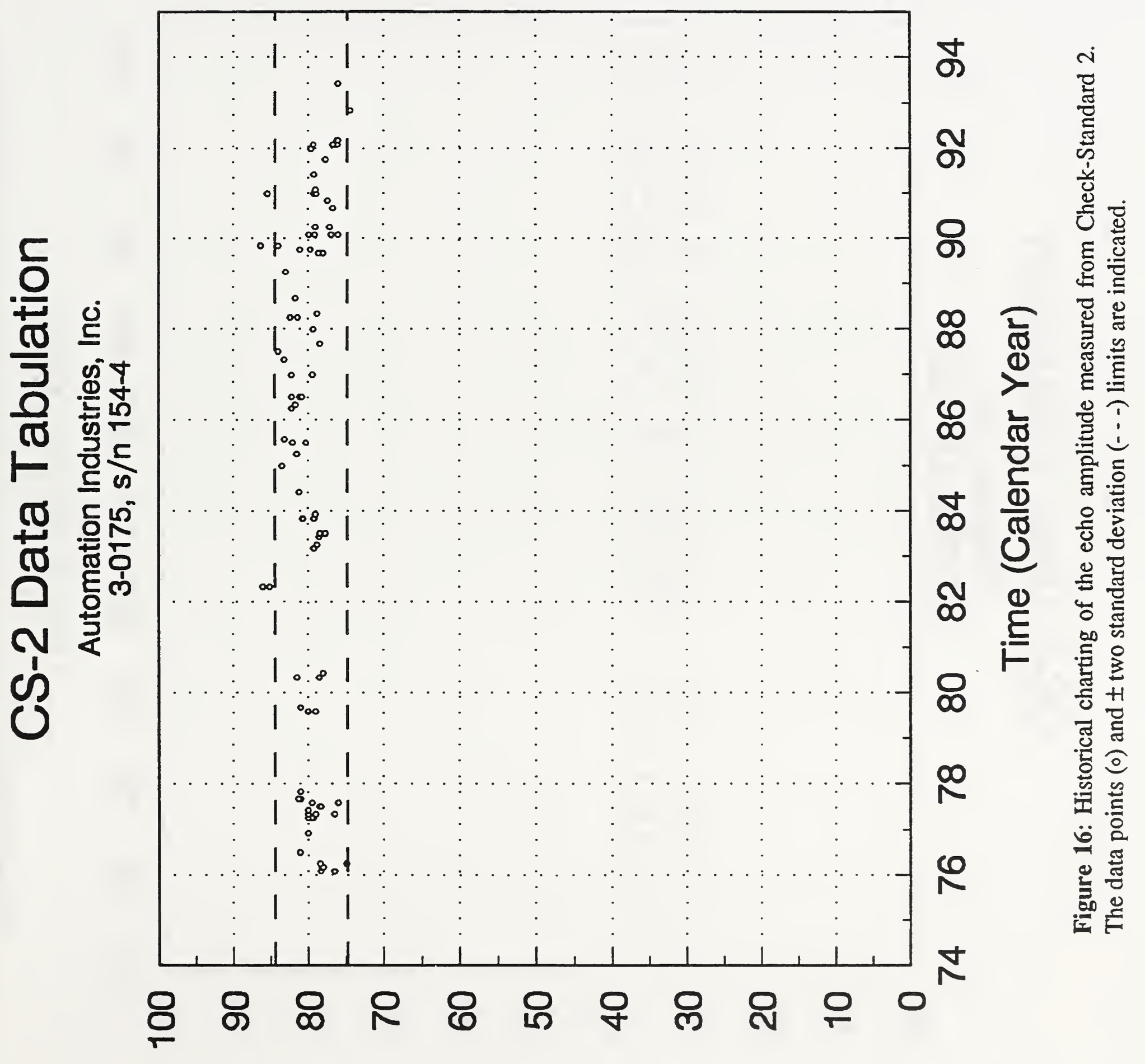

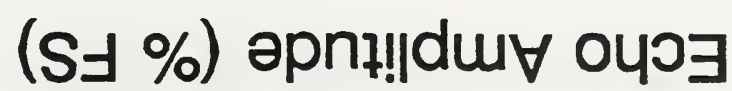




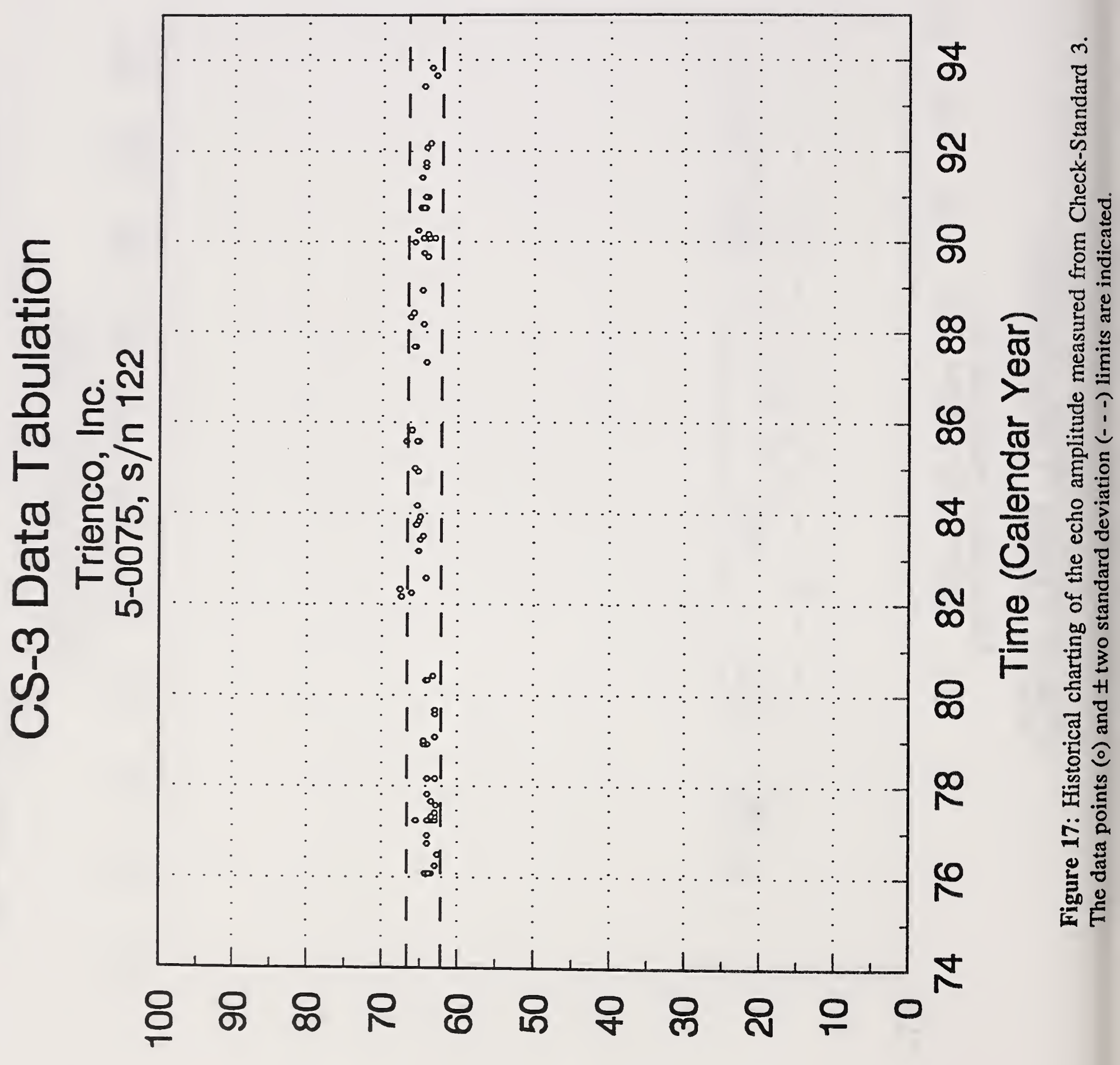

(S 


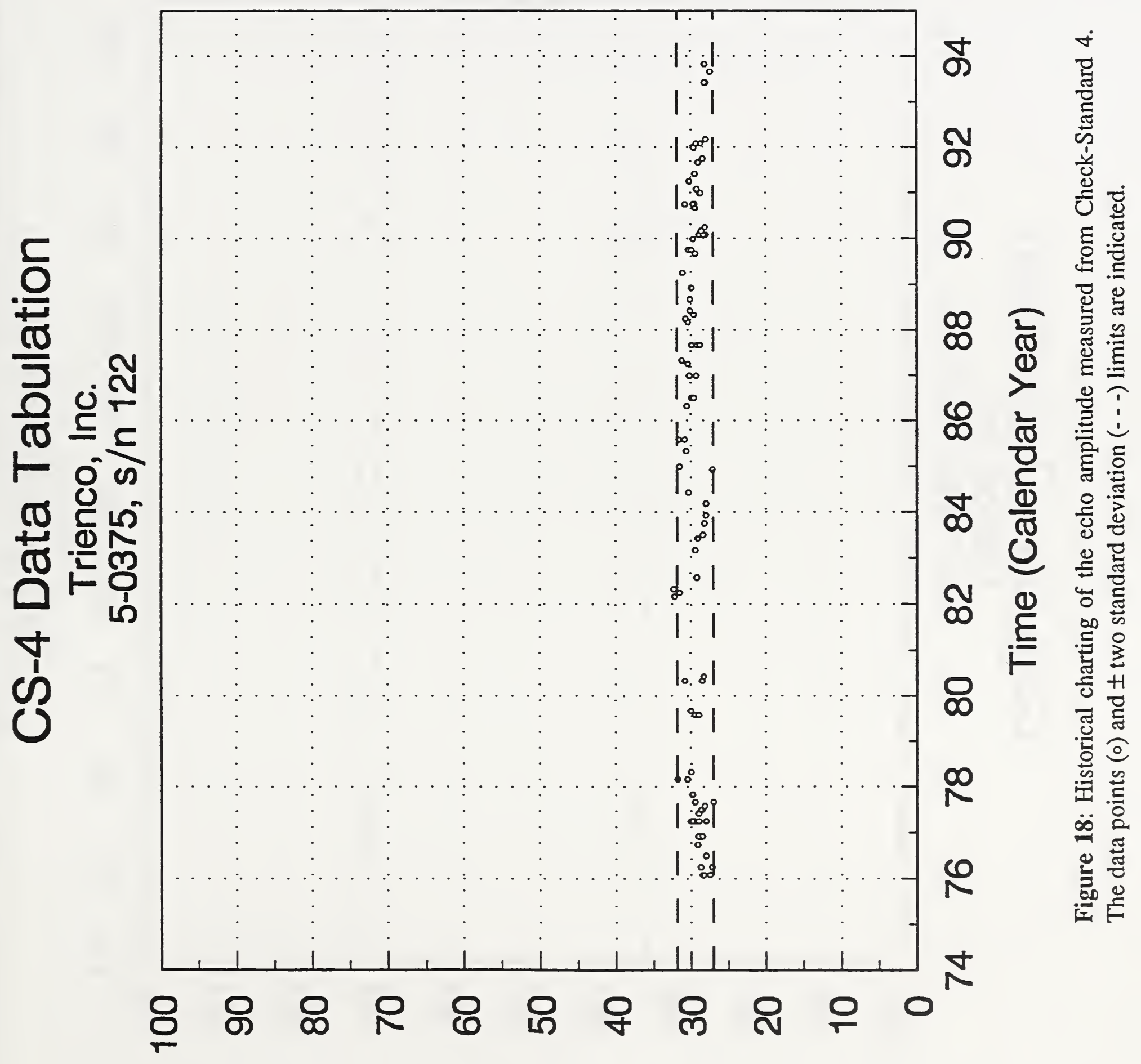

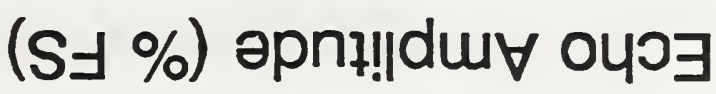




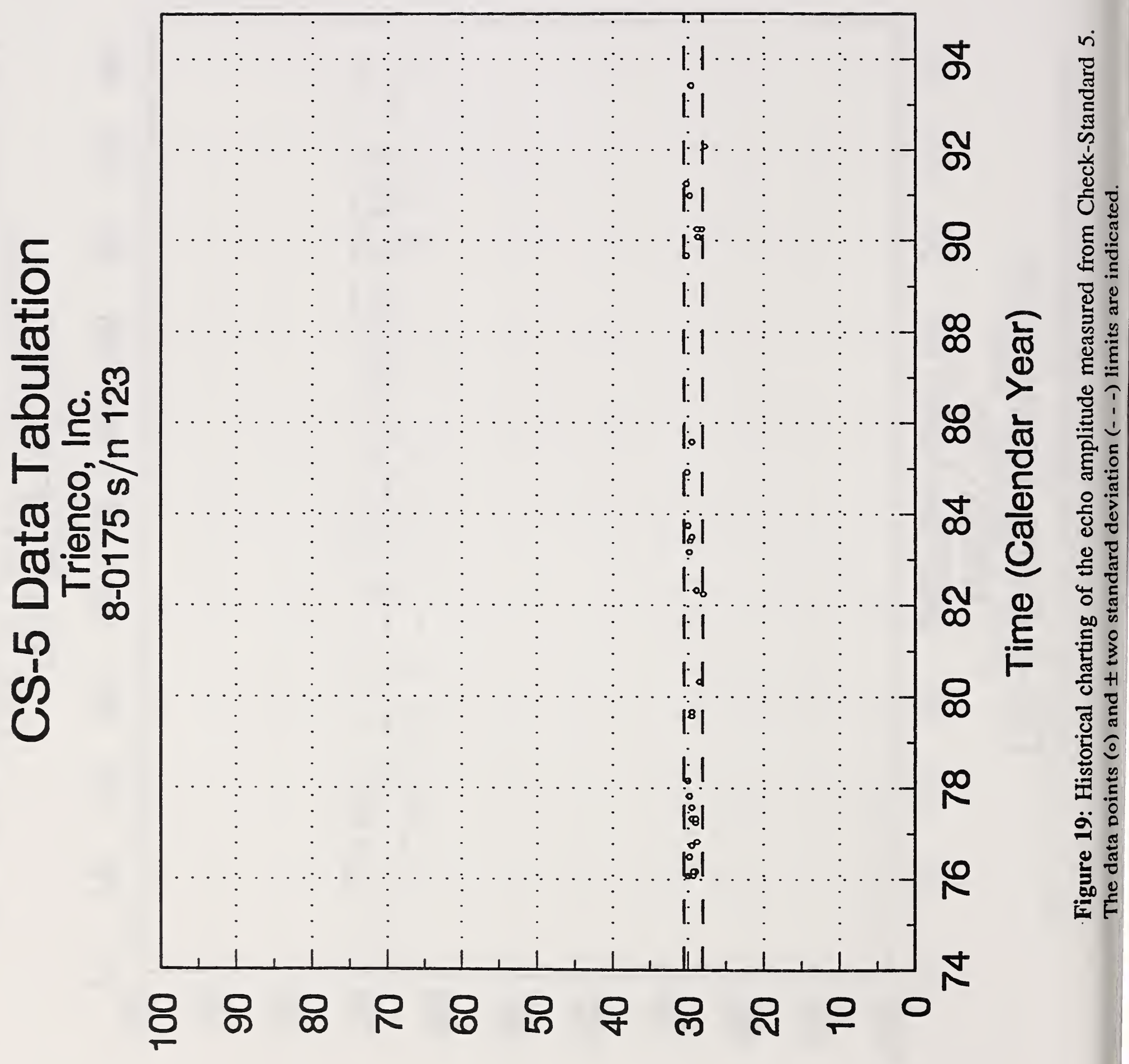

(S 


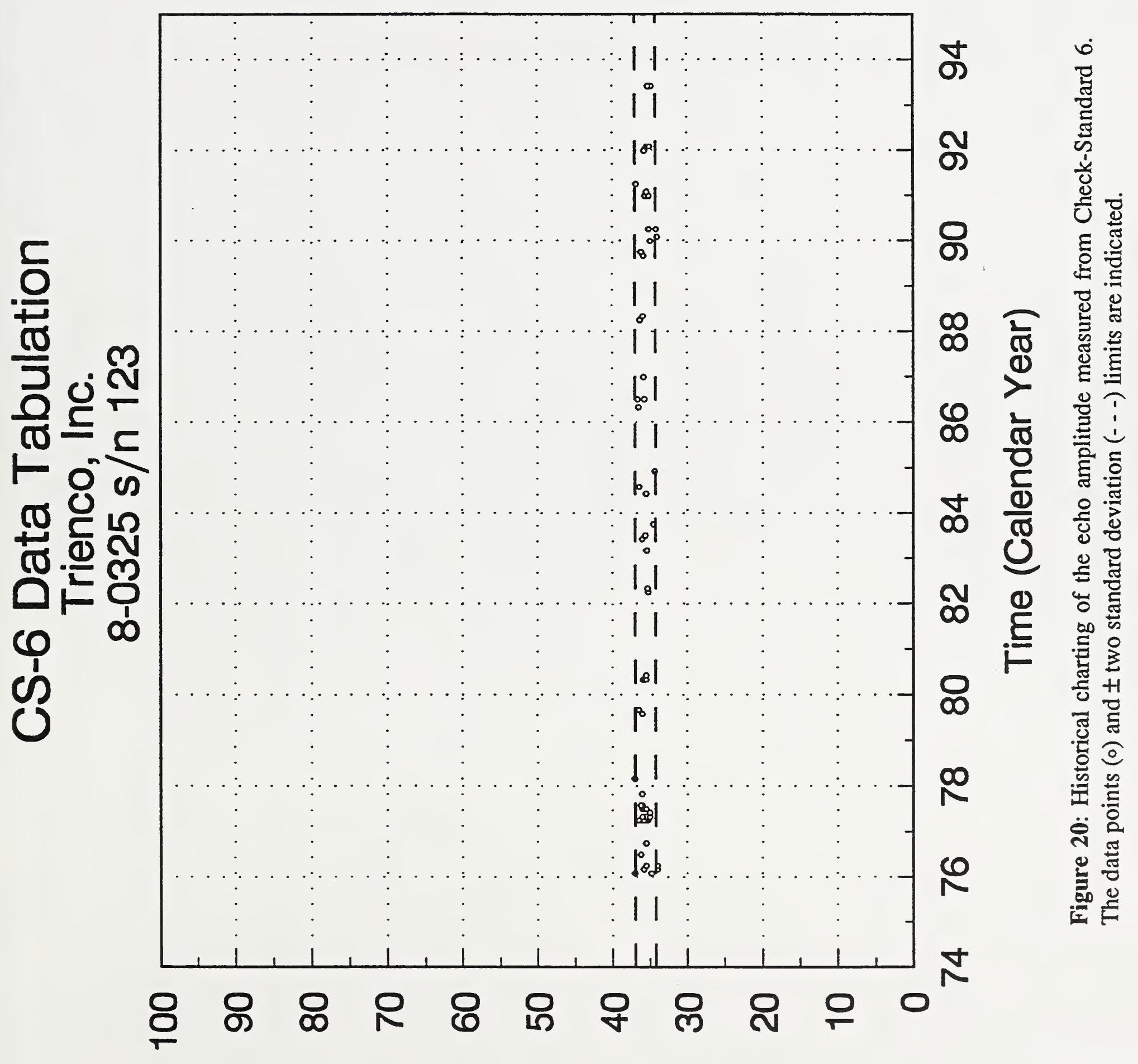

(S 


